\title{
Experimental Investigation of the Influence of Floodwater due to Ship Grounding on Motions and Global Loads
}

S. S. Bennett ${ }^{\mathrm{a} *}$

A. B. Phillips ${ }^{\text {b }}$

aFluid-Structure Interactions Group, Faculty of Engineering and the Environment, University of Southampton, Southampton Boldrewood Innovation Campus, SO16 7QF, UK

bNational Marine Facilities, National Oceanography Centre, Southampton, UK

*corresponding author, S.S.Bennett@soton.ac.uk, +44(0)2380 593035 


\title{
Experimental Investigation of the Influence of Floodwater due to Ship Grounding on Motions and Global Loads
}

\begin{abstract}
High profile collision and grounding incidents show that safety standards for ships need improvement to ensure ship survivability and reduce the potential for loss of life. An experimental investigation into the influence of floodwater, and transient flooding on the motions and structural response of a ship hull following a grounding incident is presented. Results show that floodwater can have a significant effect on the magnitude of ship responses; testing of the transient flooding case provides the opportunity to quantify the magnitude of these changes as well as the time to flood by provision of intact and flooded data during a single test. The movement of the floodwater free surface shows some substantial second order sloshing effects when close to the ship peak response, but little movement in higher frequency waves. Comparisons to classification design rules indicate that there is scope for further assessment of safety margins, including investigation of global responses in conjunction with any local loading due to the presence of floodwater. Future work will look at improving the modelling of the floodwater free surface and carrying out further transient flooding testing in order to better quantify the effect of a ship grounding incident on the survivability of a vessel.
\end{abstract}

\section{KEYWORDS}

Damaged ship; motions; global loads; free surface; transient flooding; ship grounding

\section{INTRODUCTION}


Ship safety is of paramount importance to a vessel's operator and crew in order to ensure confidence in the operation and survivability of the ship. In an ideal situation a ship should be able to act as its own lifeboat and return to port safely following a damage incident. High profile collision and grounding incidents in the last two decades, such as those given in Table 1, have shown that there is scope to enhance safety standards for ships (Lois et al., 2004). Severe accidents can cause major economic, social and environmental problems (Zhu et al., 2002) including significant structural damage to a vessel, loss of life and environmental pollution (Pedersen, 2010). Research shows that severe accidents at sea involve over $1.5 \%$ of ocean-going vessels annually and incidents involving collision, contact and grounding damage dominate (Pedersen, 2010). Eleftheria et al (2016) further review safety levels of ship accidents and find that the frequency of accidents has increased in the last decade. This statistic, and the associated casualties, can be considered unacceptable given modern navigation technologies available.

Vanem and Ellis (2010) assessed 826 accidents involving passenger ships (including Ro-Ro ferries) between 1990 and 2006, finding that collision (15\%) and groundings (16\%) were the most common causes of accident after fire and explosion, and machinery and hull damage. For passenger vessels, fatalities are more likely with a grounding than collision incident; $5 \%$ of fatalities (including missing) associated with the 826 incidents were due to collision whilst $17 \%$ occurred during groundings (Vanem and Ellis, 2010). Evacuation times, and therefore whether the vessel capsizes, also significantly affect fatality rates. This can be seen in the incident between Eifuku Maru No. 18 and Jia Hui detailed in Table 1, where all fatalities were from the capsized Eifuku Maru (gCaptain, 2013a). If less than 5 minutes are available for evacuation the fatality rate can be as high as $96 \%$ compared to $7 \%$ if the vessel remains afloat for 90 minutes or more; the equivalent statistics for groundings are $88 \%$ and 5\% (Vanem and Ellis, 2010). Further, a disparity in size between vessels involved in a collision is also more likely to result in fatalities (e.g. the 2013 collision between the $161 \mathrm{~m}$ long Sima Sapphire and a fishing vessel). 
Further statistical studies have been performed to establish the most likely location of occurrence of damage for particular incidents; the results of these studies can be used to inform experimental and numerical modelling of vessels subject to damage. In particular, the extent of the damage (in terms of length and girth) will have significant strength implications for a vessel, particularly if located in the amidships region where the global hull strength is concentrated (Zhu et al., 2002); hence it will affect the global loads measured during testing. Zhu et al. (2002) find that the majority of grounding damage occurs at, or just forward of amidships with a girth less than $50 \%$ the ship breadth and a length generally less than $5 \%$ the ship length (and unlikely to be greater than $20 \%$ the ship length). Furthermore, a larger vessel will experience significantly greater damage extent and hull girder loads than a smaller vessel during grounding (Pedersen and Zhang, 2000). Collision incidents are more complicated as the damage location and extent will depend on the relative angle between the colliding vessels (bow-bow or bow-side for example), as well as the relative sizes of the colliding vessels. Pedersen and Zhang (2000) show that there is a $25 \%$ probability of damage extending for more than $15 \%$ of the ship length for vessels longer than $100 \mathrm{~m}$, and $17 \%$ for vessels shorter than $100 \mathrm{~m}$. Severe damage incidents have been known to cause a vessel to split in half, more common when grounding or structural failure is being considered (e.g. the MV Rena in 2011 or the MV Smart in 2012); a colliding vessel is more likely to be vulnerable to sinking due to hull penetration.

The relatively high frequency of damage incidents, and the structural implications associated with them, makes it important to better understand the survivability of ships subject to damage - not only the motions, but also the global loads (specifically the vertical bending moment) that a ship hull is subject to when damage occurs. Kim et al (2013) for example use a risk-based approach to investigate safety guidelines for the ultimate hull girder strength of a grounded containership with a view to developing acceptable damage criteria and salvage or rescue techniques. However, further effects due to damage such as water influx, movement of floodwater within the hull (hence free surface effect) and the abnormal load distribution created within the hull by the ingress of floodwater, will have a significant effect on ship structural response. As a first stage, these are aspects that need to be investigated experimentally in order to gain an understanding of the interaction between the 
interaction between the ingress of floodwater into the hull and the associated change in ship responses (ITTC, 2011).

To date, experimental investigations into damaged ship responses are somewhat limited. Those that have been conducted focus on either the vessel response (motions and global loads) or the behaviour of floodwater inside a damaged compartment but not the interaction between these effects.

One of the most extensive investigations into ship response is that by Korkut et al. (2004) and Korkut et al. (2005) into the six degree of freedom motions and global loads of a Ro-Ro ferry subject to symmetric, two compartment damage. A flexible model hull was used and results found that the motions and vertical and horizontal bending moments are less in the damaged than intact condition for a Ro-Ro in beam seas. Palazzi and de Kat (2004) investigated the motions of a damaged frigate and the potential for capsize following damage using a rigid model. Lee et al. (2007) presented experimental results for the motions of a damaged Ro-Ro vessel subject to three different damage locations - bottom, side shell and bow visor damage. The model was flexibly moored, and the damage extent in each case was based on the analysis of maritime casualties and measurements were taken of the six degree of freedom motions, accelerations and the floodwater height within the damage compartment. Time histories were obtained of the change in ship motions during floodwater ingress into each damaged compartment. Lee et al. (2012) used a passenger ship hull to assess vessel motions and the free surface of floodwater inside a damaged compartment. Begovic et al. (2013) investigated the motions of an intact and damaged frigate in head, beam and quartering seas at zero speed including the effect of having the model either freely drifting and restrained. Six degree of freedom motions were measured using a motion capture technique and two-compartment, symmetric flooding was assumed. In general the model was in a steady flooded state prior to commencement of the test, although for the beam seas case tests were conducted with the damage aperture open to the waves (note that the damage aperture was positioned on the side of the vessel, making it representative of collision damage). Manderbacka et al. (2015) conducted an investigation into the transient flooding of a box shaped barge. The investigation focused on the change in roll damping 
with and without the inclusion of flooded water, and the effect of division of the flooded compartment (both symmetric and antisymmetric). Video imagery was used to measure the flooded water surface within the barge. A recent publication is that of Acanfora and de Luca (2016) which assesses the influence of the location of damage (side or bottom damage) on the roll decay, and the sway, roll and heave RAOs of a stationary passenger ferry in still water and beam on to regular waves. Results show that the different damage conditions significantly affect the motions experienced and highlight the need for further research, as presented in this paper.

There are clear indications here that more research is required into ship safety and whether vessels meet current safety standards. Although previous research has looked at ship motions during transient flooding at zero speed, assessing the structural response is considered by the authors to be particularly important as ship flexibility will change substantially when a damage opening occurs. Furthermore, recent events such as the sinking of Costa Concordia in 2012 demonstrate that a ship does not automatically become stationary as soon as damage occurs and therefore the influence of forward speed should also be addressed. How the floodwater behaves inside the ship following damage will indicate the relative impact of the additional mass due to floodwater in the vessel versus the free surface effect of the moving floodwater on the ship responses during a damage incident. With the number of damage incidents increasing in the last decade, it is also imperative to obtain an indication of the ability of a vessel to meet current design standards following damage.

The focus of this paper is therefore to investigate the influence of floodwater, transient flooding and forward speed on the motions and structural response of a ship hull travelling in regular waves. The location and extent of the damage is considered representative of a typical grounding scenario. An assessment of the movement of the floodwater free surface in the damaged compartment is undertaken. Comparisons are made of the global structural responses to current ship design rules (Lloyd's Register, 2015) in order to assess the likelihood of the survivability of a damaged vessel. This research builds on the work presented in Bennett and Phillips (2015a, 2015b, 2016). 


\section{EXPERIMENTAL SET UP}

\subsection{TEST FACILITY}

Experiments were conducted in the Southampton Solent University towing tank which is $60 \mathrm{~m}$ long, $3.7 \mathrm{~m}$ wide and $1.86 \mathrm{~m}$ deep with a maximum carriage speed of $4.5 \mathrm{~ms}^{-1}$. Unidirectional regular waves were generated using a single, motor-driven paddle wavemaker. Wave reflections from the absorption beach (measured using the technique of Isaacson (1991)) were less than 10\% (Denchfield, 2011).

\subsection{MODEL HULL ARRANGEMENT}

\subsubsection{HULL DESIGN}

Tests were conducted using a representative hull of a Leander class frigate, at a scale of 43.62, with the principal particulars in Table 2 (Denchfield, 2011). In Table 2 the pitch gyradius was obtained by swinging the model in a pendulum manner; the VCG was obtained from the VCG locations of the individual components of the model. This ship type was selected as survivability following damage is a key consideration for a naval vessel (which may be subjected to damage as a result of its normal operation) but a vessel type for which, with the majority of previous experiments focusing on commercial vessels, only limited experimental damage modelling has been carried out. The model hull was a segmented, flexible backbone model constructed of four rigid segments attached to a uniform $602 \mathrm{~T} 6$ aluminium backbone beam. The backbone beam was designed such that the model was capable of reproducing the 2-noded bending of the full-scale ship by choosing a cross-section which gave the scaled bending stiffness of the full scale vessel and had the correct scaled 2-node bending natural frequency assuming the ship could be represented as a free-free beam. Full details of the design of the hydroelastic model including the backbone selection are given in Denchfield (2011). Figure 1 presents a schematic of the model hull whilst Figure 2 shows the experimental set-up. A body plan of the model hull can be found in Bennett et al. (2013). 


\subsubsection{DAMAGE DESIGN AND EXTENT}

The damage was placed in Segment 3 in Figure 1, located between amidships and the forward quarter, with the damage incident being in the bottom of the vessel with a breadth of $20 \%$ the ship breadth and a length of $10 \%$ the ship length. A schematic of the damaged compartment is show in Figure 3, including the location of the damaged opening for the transient flooding tests. The damaged compartment and extent were chosen based on information in literature which states that grounding incidents most commonly cause damage at or just forward of amidships with a breadth less than $20 \%$ the ship breadth and a length which is less than 5\%, and unlikely to be greater than $20 \%$, of the ship length (Zhu et al., 2002). The change in ship hydrostatics with the inclusion of floodwater is given in Table 3.

\subsection{TEST PROGRAM}

Experiments were conducted in regular waves with the parameters given in Table 4, chosen to give a complete response amplitude operator (RAO). All waves were tested at a height of $50.30 \mathrm{~mm}$ at model scale, corresponding to $\mathrm{H} / \mathrm{L}_{\mathrm{OA}}=0.02$ and a full-scale wave height of $2.19 \mathrm{~m}$. Experiments were conducted in head seas at Froude numbers, Fn, of zero and 0.157, corresponding to full-scale speeds of 0 knots and 10 knots.

Tests were conducted with the ship hull for three scenarios:

1. Intact: Intact hull with the principal particulars given in Table 1, at $\mathrm{Fn}=0$ and $\mathrm{Fn}=0.157$

2. Flooded: Damaged hull with floodwater present in the segment forward of amidships prior to the start of a test run, at $F n=0$ and $F n=0.157$

3. Transient: Intact hull subjected to damage and transient flooding in the damaged segment during the test run at $\mathrm{Fn}=0$ and $\lambda / \mathrm{LOA}_{\mathrm{OA}}=1.18$ only. Note that the responses analysed in this case and compared to the intact and flooded conditions will be those following the flooding in 
the compartment reaching its steady state. However the responses that accompany the freeflooding of the compartment will also be investigated.

During scenario (2) the mass of floodwater added to the segment was identical to that which represented steady state during the transient flooding tests. A cross-section through the damaged compartment, showing the static floodwater level (at $107.25 \mathrm{~mm}$ above the longitudinal centre of the compartment) is shown in Figure 4. For scenario three, damage was located in the keel of the model, as indicated in Figures 3 and 4. At the start of each test the damage opening was sealed with aluminium foil which acted as a robust but easily removable boundary between the water and the internal compartment. The ship was allowed to reach steady state motions in the intact condition; a sharp knife was then used to rapidly remove the foil boundary allowing flooding to take place. Once flooding had completed in scenario (3) the damage condition of the ship was identical to that in scenario (2).

Measurements were taken of the encountered wave profile at amidships, heave, pitch, vertical bending moment and the internal wave profile within the damaged compartment, all sampled at $100 \mathrm{~Hz}$. Encountered and internal wave profiles were measured using resistance type wave probes. Heave and pitch were measured via a dynamometer at the LCG of the model. Vertical bending moments were recorded using Vishay CEA-13-240-UZ-120 strain gauges arranged in a full bridge strain gauge arrangement. Measurement locations were amidships, and the forward and aft quarter. Strain gauges were calibrated prior to testing by arranging the backbone as a pinned-pinned beam subjected to a point load. Video imagery during testing was recorded using two GoPro Hero 2 cameras.

\section{RESULTS}

\subsection{RAOs}

Figures 5 and 6 present the heave, pitch and vertical bending moment RAOs for the ship measured in the intact, flooded and transient conditions at $\mathrm{Fn}=0$. The equivalent comparisons for the intact and 
damaged conditions at $\mathrm{Fn}=0.157$ are in Figures 7 and 8 . The wave frequencies tested in were chosen to give a complete RAO for each response whilst also being within the accurate operating range of the towing tank. Vertical bending moment was non-dimensionalised by $\rho g B L^{2} \eta$ where $\rho$ is the density of water, $g$ acceleration due to gravity, $B$ the ship breadth at amidships, $L$ the ship length and $\eta$ the wave amplitude. In these, and following, RAO plots multiple values are shown around the central wave frequency tested as the results from repeat tests are plotted individually (see Section 3.6 for corresponding uncertainty analysis). Numerical RAOs for this ship for comparison can be found in Bennett et al. (2013); future work will carry out a more in depth comparison between experimental results and numerical simulation.

These results demonstrate that there is a small change in the heave RAO between the intact and flooded conditions; a more substantial reduction in the magnitude of the pitch RAO occurs with the inclusion of damage at both $\mathrm{Fn}=0$ and $\mathrm{Fn}=0.157$. This is likely to be due to the additional mass of floodwater changing the mass distribution of the vessel and preventing it from pitching as much in the waves. The magnitude of the reduction appears independent of Froude number. When looking at the vertical bending moment RAOs the greatest increase in magnitude from the intact to damaged condition is seen at the forward quarter and the least increase at the aft quarter. The increase furthermore becomes more pronounced as the Froude number of the ship increases. One anomalous result is seen in the amidships vertical bending moment in the flooded condition at approximately 1.0 $\mathrm{rad} / \mathrm{s}$. Further confirmation of the reason for this is required.

In general the results in the transient condition, assessed at $\mathrm{Fn}=0$, are in-line with those measured in the flooded condition. This is expected as the amount of floodwater in the model was the same in the transient condition once flooding had reached steady state, as it was in the flooded condition. The slight differences are seen in the heave results and the vertical bending moment at the forward quarter; these require investigation in more detail. 
What is also of interest is the distribution of the RAOs between the hogging and sagging directions of the response. RAOs in addition to those in Figures 5-8 were calculated using the double positive amplitude, and the double negative amplitude of the response. Little difference was seen in the heave and pitch responses from that presented in Figures 5 and 7. The vertical bending moment RAOs using this secondary calculation method are presented in Figures $9(\mathrm{Fn}=0)$ and $10(\mathrm{Fn}=0.157)$, focusing on the intact and flooded results only.

Some interesting trends are visible in the results in Figures 9 and 10. The sagging vertical bending moment RAO (double negative amplitude) is of a higher magnitude than the hogging vertical bending moment RAO at zero speed. This difference is most visible at the forward quarter and when the ship is in its flooded condition. The disparity between the magnitude of the hogging and sagging responses becomes more pronounced when the ship is travelling at a Froude number of 0.157 . In particular, it is noticeable at amidships and the aft quarter the trend in the relative magnitudes of the intact and damaged RAOs reverses in the hogging condition compared to all other results, with the intact RAO having a greater magnitude than the damaged RAO. These differences in hogging and sagging at different locations is likely to be due to the floodwater mass being added close to amidships whilst differences in the relative magnitudes of the intact and damaged RAOs are due to the presence of floodwater resulting in a shift of the vertical bending moment distribution of the vessel. These results highlight the importance of understanding not only the overall global response of the ship, but also its distribution between hogging and sagging conditions and how the damage state will affect this distribution.

\subsection{MOVEMENT OF FLOODWATER FREE SURFACE}

Recordings were made of the movement of the floodwater free surface (the internal wave profile) at a distance halfway along the damage opening, $148 \mathrm{~mm}$ from the aft bulkhead of the flooded compartment at each of the regular wave frequencies tested, and both $F n=0$ and $F n=0.157$. Results showing the change in internal wave profile shape are presented in Figures 11 and 12. Note that the 
wave profile should oscillate around zero in each of these plots, but a slight offset was present in the calibration of the wave probe in some cases.

At Fn $=0$ there is a clear second order sloshing effect visible at a wave frequency of $4.49 \mathrm{rad} / \mathrm{s}$ model scale $\left(0.68 \mathrm{rad} / \mathrm{s}\right.$ full scale); this corresponds to $\lambda / \mathrm{L}_{\mathrm{OA}}=1.18$, so close to the peak response of the ship, and is visible through the secondary peaks in the otherwise reasonably regular internal wave profile. The same effect is seen at Fn $=0.157$ wave frequencies of $0.53 \mathrm{rad} / \mathrm{s}$ and $0.59 \mathrm{rad} / \mathrm{s}$ at full scale, hence $\lambda / \mathrm{L}_{\mathrm{OA}}=1.54$ and 1.95. This shift in the wave frequencies at which sloshing effects occur is due to the change in encountered wave frequency with the introduction of forward speed and constitutes a change in the worst-case scenario for the vessel in terms of movement of floodwater within the compartment. Figures 13 and 14 demonstrate the presence of these secondary frequencies in the internal wave profile by showing an fft of the profiles corresponding to Figure 11 (c) and (d), and Figure 12 (b) and (c). Frequency spikes are clearly visible at higher frequencies than the wave frequency in all cases. At higher wave frequencies the internal wave probe shows minimal internal waves as demonstrated in Figure 11 (e) and Figure 12 (d) and (e). This indicates that the variation in the RAO from the intact condition at these frequencies is due to the change in mass and mass distribution due to the addition of floodwater rather than any sloshing effects. Sloshing effects are of more importance at the frequencies showing a large internal wave profile.

\subsection{CHANGE IN RESPONSE MAGNITUDE FROM THE INTACT TO DAMAGED CONDITION}

Figure 15 shows the change in all responses (heave, pitch, vertical bending moment at amidships and the quarters, and the internal wave profile) as the ship progressed from the intact to damaged condition during the transient tests.

From Figure 15 it is clearly visible how the responses changed as floodwater ingress occurred, in terms of magnitude and location of the zero level for each measurement. These values are quantified 
in Tables 5 and 6, as the percentage increase in response as a percentage of the mean intact response, and the change in zero level of each response respectively.

Table 5 demonstrates that with floodwater ingress there is a reduction in the magnitude of heave and pitch responses of the ship, by $16 \%$ and $8 \%$ respectively. The most significant differences in the vertical bending moment are seen at the forward quarter and amidships. A substantial (24\%) increase in the magnitude of the vertical bending moment occurs at the forward quarter which would be a cause for concern if such a flooding incident were to occur. A corresponding reduction of $14 \%$ in the vertical bending moment at amidships also occurs. The location of the flooded compartment means that the change in vertical bending moment at the aft quarter is minimal. The results for the motions presented here agree well with trends in results presented in Korkut et al (2004) for a Ro-Ro ferry, giving confidence in the trends seen.

When looking at the movement of the zero level for each response, the drop in the location of the heave response is due to the floodwater ingress causing the ship to sink to a deeper draught than in the intact condition. If the change in the heave response zero level is related to the change in the VCG in the damaged condition, it can be seen that it is almost double $-0.87 \mathrm{~m}$ compared to an increase in VCG of $0.49 \mathrm{~m}$. A slight positive movement in the mean location of the pitch response is seen; this corresponds to the trim of the ship becoming more bow down. Substantial drops are seen in the location of the zero location of the forward quarter and amidships vertical bending moments; these correspond to the vessels static vertical bending increasing in the sagging direction at these location. As with the change in magnitude of the response, there is no change in the vertical bending moment at the aft quarter due to the minimal effect of the floodwater at this location.

Referring back to Figure 15, it can be seen that the time to flood and reach steady state appears to be relatively short (approximately 6.3 seconds when looking at the evolution of the internal wave profile). This may be a result of the size of the damage incident relative to the size of the flooded compartment; future work will look at this time to flood, and its scalability to a full scale vessel. Furthermore when 
looking at the behaviour of the vessel during the flooding process, it appears that the rate of flooding (hence change in responses) is relatively linear over the first 4 seconds of the time to flood; for the remaining 2.3 seconds there is a reduction in the rate of change of the responses.

\subsection{PHASING}

Of importance when assessing the response of the damaged ship is the phasing of the vertical bending moment and internal wave surface relative to the encountered wave profile, hence pitch response, and any changes that may be seen between the intact and damaged conditions. Of particular interest in this paper are any changes seen at the forward quarter, since these locations are where the majority of changes in the response due to the floodwater ingress have occurred.

Figures 16 shows the phasing between the wave profile and corresponding pitch response and vertical bending moment at the forward quarter for both Froude numbers tested, and the peak of the RAO curve with the ship in its intact condition. The equivalent comparison for the flooded condition is in Figure 17, and for the flooded vessel and the amidships vertical bending moment in Figure 18. The phasing between the encountered wave profile, pitch, and internal wave profile is demonstrated for the flooded ship at both Froude numbers in Figure 19. The distance between measurement locations (with amidships designated as $\mathrm{x}=0$ ) is given in Table 7 .

These example results show the effect of both ship speed and damage on the phasing between the ship responses and the encountered wave profile. In terms of the vertical bending moment and the pitch responses, the ship speed has little effect on the phasing between the encountered wave profile and the response. However, looking at Figure 19, there is a change in the phasing between the internal wave profile within the compartment and the encountered wave profile, hence the pitch response, at Fn = 0.157 compared to $F n=0$. This is visible as a more substantial lag in the peak of the internal wave profile relative to the peak of the encountered wave profile at $\mathrm{Fn}=0$ compared to $\mathrm{Fn}=0.157$. 


\subsection{TRANSIENT FLOODING SIMULATIONS}

As an initial step in characterising the flow within the damaged compartment, a schematic has been produced of the water movement within the compartment during the transient flooding tests, based on the GoPro camera imagery and the recorded internal wave profile. Figure 20 presents this schematic, for the typical duration of one period of the internal wave once flooding has reached its steady state, including measurements of the elevation of the water surface above the mean surface of the floodwater in the compartment with no external wave action acting on the ship.

The first point to note from this schematic is that there is an asymmetry present in the internal wave profile due to the aforementioned sloshing effects seen in the internal wave, which accounts for the internal wave trough not occurring at the aft of the flooded compartment at exactly half the wave period of the internal wave.

The schematic further shows that the elevation above the mean water level during the movement of the free surface is not the same at the fore and aft of the compartment, and also different to the drop in water level below the mean at the opposite end of the compartment. This is due to the flooded compartment not being box shaped, but having a longitudinal taper and change in depth between amidships and the forward quarter.

These two points demonstrate the need to produce schematics or simulations such as this, and of ensuring an accurate simulation of the shape of the flooded compartment as well as the movement of the internal wave surface. By increasing the number of wave probes within the damaged compartment, and the amount of video imagery recorded the accuracy and level of detail in these simulations will also be improved.

\subsection{UNCERTAINTY ANALYSIS}


An uncertainty analysis was conducted using key cases from the test program. Uncertainty calculations were conducted for the vessel intact and flooded, at both Froude numbers tested and also for the transient case. Uncertainty was calculated using the technique of Coleman and Steele (1999), assuming 95\% confidence in experimental measurements. The same regular wave condition was used in each case in order to make results comparable, namely that corresponding to $\lambda / \mathrm{L}_{\mathrm{OA}}=1.18$. Results are presented for each of the responses measured in Tables 8 and 9. Where no uncertainty value is given, it is either not applicable (e.g. the internal wave profile in the intact case) or data acquisition issues meant that only two repeat runs were available for that measurement.

Results show uncertainty levels of $5 \%$ or less in the majority of cases with no uncertainty greater than $10 \%$ which is acceptable.

\section{COMPARISON TO SHIP DESIGN RULES}

An initial comparison between the experimental results presented here and the distribution of allowable wave induced vertical bending moment (WVBM) calculated from the Lloyd's Register Classification Rules for Naval Ships (Lloyds Register, 2015). Figure 21 presents results for this comparison for the ship at $\mathrm{Fn}=0$ and $\mathrm{Fn}=0.157$ in each of the regular waves tested. Experimental results are shown for the forward and aft quarters and amidships, for the data presented previously. Rules values of WVBM were calculated assuming the vessel was suited to worldwide operation, and therefore a design sea state with a significant wave height of $5.5 \mathrm{~m}$ was assumed. For the zero speed case the ship peak response occurred at a wave frequency of $0.68 \mathrm{rad} / \mathrm{s}$ whereas for $\mathrm{Fn}=0.157$ it occurred at a wave frequency of $0.79 \mathrm{rad} / \mathrm{s}$. In addition to the experimental results in full scale wave heights of $2.19 \mathrm{~m}$, two further sets of experimental scaled results (assuming linear scaling is possible) are shown: (i) corresponding to $\mathrm{H}=5.5 \mathrm{~m}$, the condition for which rules values are calculated and (ii) corresponding to $\mathrm{H}=11.0 \mathrm{~m}$, at which point the rules values are exceeded. 
Figure 21 shows that in general the vertical bending moments of the damaged vessel measured during experiments are below the current recommended values according to classification society rule (Lloyds Register, 2015). There is less of a safety margin when the ship is travelling at speed compared to when it is stationary in both the intact and damaged cases. This is particularly visible around the peak response wave frequency (Figure $21 \mathrm{~g}$ ) at $\mathrm{Fn}=0.157$, when the results are in general close to the rules values at all three locations at which measurements were taken.

When experimental results are scaled to a wave height corresponding to that for which the rules values are calculated, this leads to a significant loss of safety margin, particularly at speed and around the peak response of the vessel. This reduction in safety margin is something which needs looking at in greater detail, as whilst the safety margin in the flooded case relative to the intact case does not dramatically increase, additional local loading effects due to the floodwater being present which do not occur in the intact case may result in these safety margins being unacceptable for a damaged vessel and result in its inability to "return to port" following damage - a key factor when considering ship safety.

The rules values are just exceeded for the forward speed case prior to the stationary case, at a wave height of $11.0 \mathrm{~m}$. In reality, this study has assumed linear scaling whereas previous research (Bennett et al., 2013; Bennett et al., 2015) has shown that in larger encountered wave heights substantial nonlinearities will affect the severity of ship motions and global loads meaning that this exceedance of the rules values will occur sooner. When these nonlinearities dominate, the response of the damaged ship will furthermore be key in the ability of the vessel to safely return to port following damage. Therefore nonlinearities in response following flooding is something that should be investigated further. In addition this comparison was made between responses measured in regular waves during experiments and maximum allowed responses in irregular seas according to classification society rules. Future work will use a spectral analysis approach to further assess the influence of damage relative to the rules values. 


\section{CONCLUSIONS}

It has been identified that the frequency of ship accidents has increased in the last decade (Eleftheria et al., 2016) and therefore a better understanding of ship safety following damage is required. This includes an understanding of the influence of forward speed, the floodwater free surface, and whether the responses experienced by the vessel still meet with current design rules, thus indicating the ability of the vessel to withstand the damage incident. This paper addresses this problem through an experimental investigation of the influence of floodwater on the motions and structural response of a frigate hull in regular waves. Characterisation of the movement of the floodwater free surface and its likely influence on ship responses in different wave frequencies is undertaken, as is initial research into the influence of transient flooding. Experimental results for global wave-induced loads are compared to current ship design rules in order to provide a first indication of the survivability of the ship following damage, and therefore the level of safety available.

An uncertainty analysis was conducted which demonstrates that uncertainties in experimental results are in general less than $5 \%$ and always less than $10 \%$ indicating a high level of confidence in experimental results.

Results show that in the flooded scenario the heave and pitch responses of the vessel reduce. An increase in vertical bending moment response is seen at the forward quarter, in the vicinity of the damaged compartment, whilst there is a corresponding reduction at amidships; this increase is more substantial when forward speed is introduced. Furthermore significant differences in the hogging and sagging response of the ship are seen with the inclusion of floodwater.

Analysis of the internal wave profile in the flooded compartment has indicated second order sloshing effects are present at encountered wave frequencies close to the peak response of the ship. These effects are likely to dominate the severity of the responses experienced by the ship around these wave frequencies. Higher wave frequencies constitute less of a risk as the magnitude of response is less and 
there is a substantial reduction in the movement of the floodwater within the compartment; thus at these frequencies it will be the presence of the floodwater mass abnormally loading the ship rather than free surface effects that will have the greatest influence on ship responses.

An investigation of the phasing between the ship responses and the encountered wave profile has been shown to be independent of ship speed. However speed does affect the phasing between the sloshing of the floodwater and the pitch response of the ship; this will affect how severe the effect of the sloshing is on the ship responses as speed is introduced and requires further investigation.

The transient flooding tests have proved useful in being able to characterise the time to flood of the compartment and the change in magnitude of each response from the intact to the flooded condition. Therefore it is considered that there is value in carrying out further transient flooding tests both at zero and forward speed in order to carry out this analysis across the entire range of the ship responses.

Video imagery was used to capture the sloshing of the water in the flooded compartment and develop schematics of its movement which show some interesting asymmetries in the shape of the floodwater free surface, and its movement within the damaged compartment. Improved characterisation of the internal wave profile will help improve understanding of the influence of this movement on the ship responses.

Comparisons of experimental results to current ship classification design rules have indicated relative safety margins for the global wave-induced loads based on the experimental measurements taken at three locations along the vessel. These results need to be investigated in conjunction with any local loading effects due to the presence of floodwater within the vessel in order to definitively assess the magnitude of any reduced safety margins when damage occurs, and assess whether a ship is capable of returning to port or the consequences are likely to be more severe. 
Overall this research has demonstrated the effect of the influence of floodwater on the motions and structural responses of a vessel subjected to damage due to grounding. Future work will look at enhancing the quality of the modelling through the improved capture of the moving floodwater free surface with multiple wave probes installed in the damaged compartment as well as drawing parallels between the flooding scenario and the phenomenon of sloshing in tanks. The scalability of the time to flood will be investigated. Further investigation of the safety margins present in the loadings experienced by the ship relative to current ship design rules, in conjunction with any local loading effects and nonlinearities in response, will be used to further assess the overall safety of a vessel following damage. Furthermore a numerical model will be developed which accurately models the responses of the ship and the transient flooding within the compartment compared to that observed in experiments.

\section{ACKNOWLEDGEMENTS}

This project is partially supported by funds from the Lloyd's Register Foundation, through the Lloyd's Register University Technology Centre at the University of Southampton.

\section{REFERENCES}

Acanfora, M., and De Luca, F., 2016. An experimental investigation into the influence of the damage openings on ship response, Applied Ocean Research 58, 62 - 70

Begovic, E., Mortola, G., Incecik, A., and Day, A. H., 2013. Experimental assessment of intact and damaged ship motions in head, beam and quartering seas, Ocean Engineering 72, 209 - 226

Bennett, S. S., Hudson, D. A. and Temarel, P. 2013. The influence of forward speed on ship motions in abnormal waves: experimental measurements and numerical predictions, Journal of Fluids and Structures, 39, 154-172 
Bennett, S. S., Hudson, D. A., and Temarel, P. 2014. Global wave-induced loads in abnormal waves: comparison between experimental results and classification society rules, Journal of Fluids and Structures, 49, 498-515

Bennett, S. S., and Phillips, A. B., 2015a. Experimental investigation of the influence of hull damage on ship responses in waves, Proceedings of the $5^{\text {th }}$ International Conference on Marine Structures, Southampton, UK, $24^{\text {th }}-27^{\text {th }}$ March 2015

Bennett, S. S., and Phillips, A. B., 2015b. On the hydroelastic modelling of damaged ships, Proceedings of the $7^{\text {th }}$ International Conference on Hydroelasticity in Marine Technology, Split, Croatia, $16^{\text {th }}-19^{\text {th }}$ September 2015

Bennett, S. S., and Phillips, A. B., 2016. The dynamic response of a damaged ship in waves, under review, Ocean Engineering, 12/2015

Coleman, H.W. and Steele, W.G. 1999. Experimentation and Uncertainty Analysis for Engineers, Wiley Interscience, New York, second edition

Denchfield, S. S. 2011. An Investigation of the Influence of Rogue Waves on a Travelling Ship, PhD Thesis, University of Southampton, UK

Eleftheria, E., Apostolos, P., and Markos, V., 2016. Statistical analysis of ship accidents and review of safety level, Safety Science, 85, 282-292

gCaptain, 2013a. http://gcaptain.com/bulk-carrier-mv-smart-aground-richards-bay/, accessed 21/10/14 
Isaacson, M. 1991. Measurement of regular wave reflection. Journal of Waterway, Port and Coastal Engineering, 117, 533-569

ITTC, 2011. Final Report and recommendations to the $26^{\text {th }}$ ITTC: specialist committee on stability in waves, Proceedings of the $26^{\text {th }}$ International Towing Tank Conference, Rio de Janiero, Brazil, $28^{\text {th }}$ August $-3^{\text {rd }}$ September 2011

Kim, D. K., Pedersen, P. T., Paik, J. K., Kim, H. B., Zhang, X., and Kim, M. S., 2013. Safety guidelines of ultimate hull girder strength for grounded container ships, Safety Science, 59, 46-54

Korkut. E., Atlar, M. and Incecik, A. 2004. An experimental study of motion behaviour with an intact and damaged Ro-Ro ship model, Ocean Engineering, 31 (3-4), 483-512

Korkut, E., Atlar, M. and Incecik, A., 2005. An experimental study of global loads acting on an intact and damaged Ro-Ro ship model, Ocean Engineering, 32 (11-12), 1370-1403

Lee, D., Hong, S. Y., and Lee, G-J., 2007. Theoretical and experimental study on dynamic behaviour of a damaged ship in waves. Ocean Engineering 34, 21 - 31

Lee, S., You, J-M. and Lee, H-H. 2012. Experimental study on the six degree-of-freedom motion of a damaged ship for CFD validation, Proc. $29^{\text {th }}$ Symposium on Naval Hydrodynamics, Gothenburg, Sweden, 26-31 August 2012

Lloyd's Register, 2012. Rules and Regulations for the Classification of Naval Ships, Vol. 1, Pt. 5, Ch. 2.3

Lois, P., Wang, J., Wall, A., and Ruzton, T., 2004. Formal safety assessment of cruise ships. Tourism Management 25, 93 - 109 
Manderbacka, T., Ruponen, P., Kulovesi, J., and Matusiak, J., 2015. Model experiments of the transient response to flooding of the box shaped barge, Journal of Fluids and Structures, 57, 127-143

Palazzi, L. and de Kat, J. 2004. Model experiments and simulations of a damaged ship with air flow taken into account, Marine Technology, 41, 38-44

Pedersen, P. T., 2010. Review and application of ship collision and grounding analysis procedures, Marine Structures 23, 241-262

Pedersen, P. T., and Zhang, S., 2000. Effect of ship structure and size on grounding and collision damage distributions, Ocean Engineering 27, 1161-1179

Zhu, L., James, P. and Zhang, S. 2002. Statistics and damage assessment of ship grounding, Marine Structures, $15,515-530$

Vanem, E., and Ellis, J., 2010. Evaluating the cost-effectiveness of a monitoring system for improved evacuation from passenger ships, Safety Science 48, 788-802

\section{FIGURES}




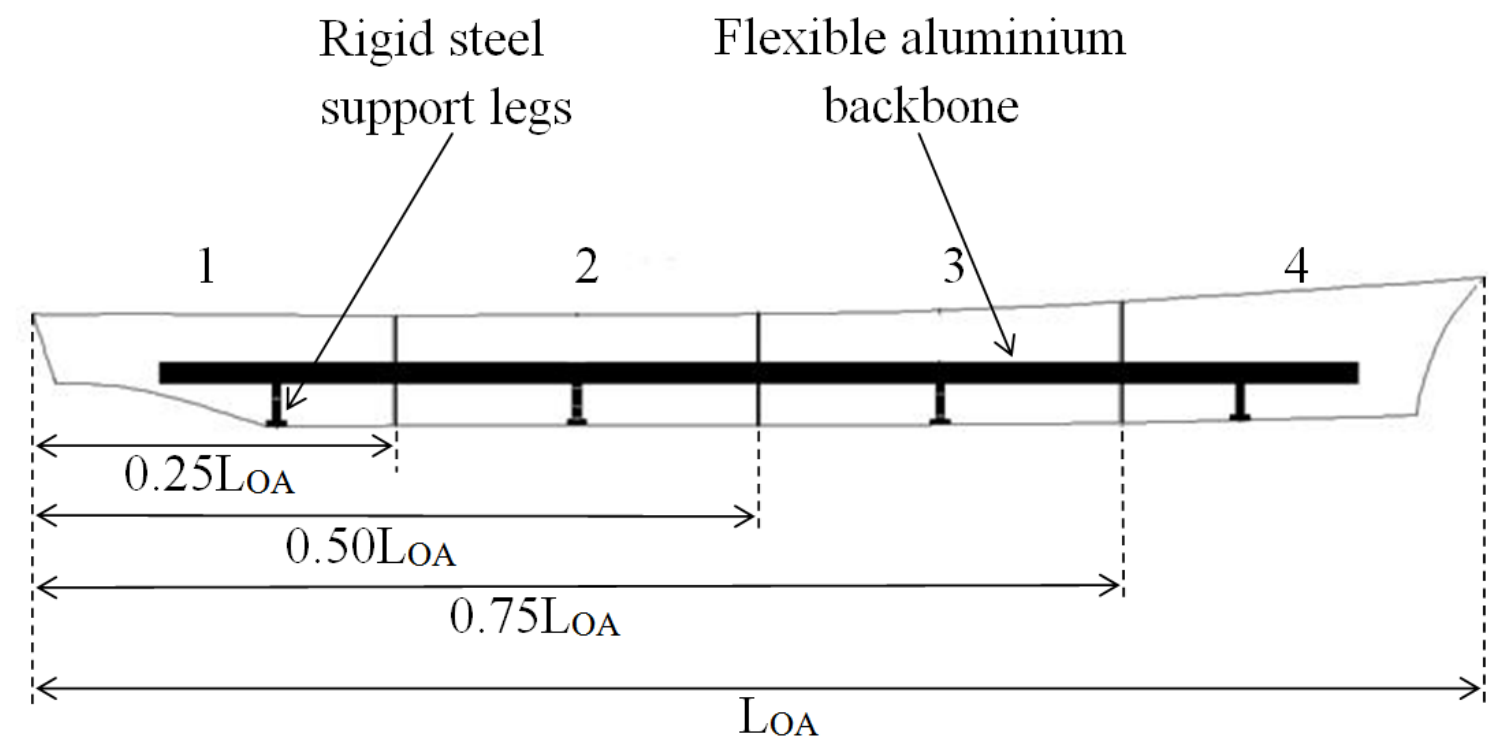

Figure 1: Schematic of flexible model hull

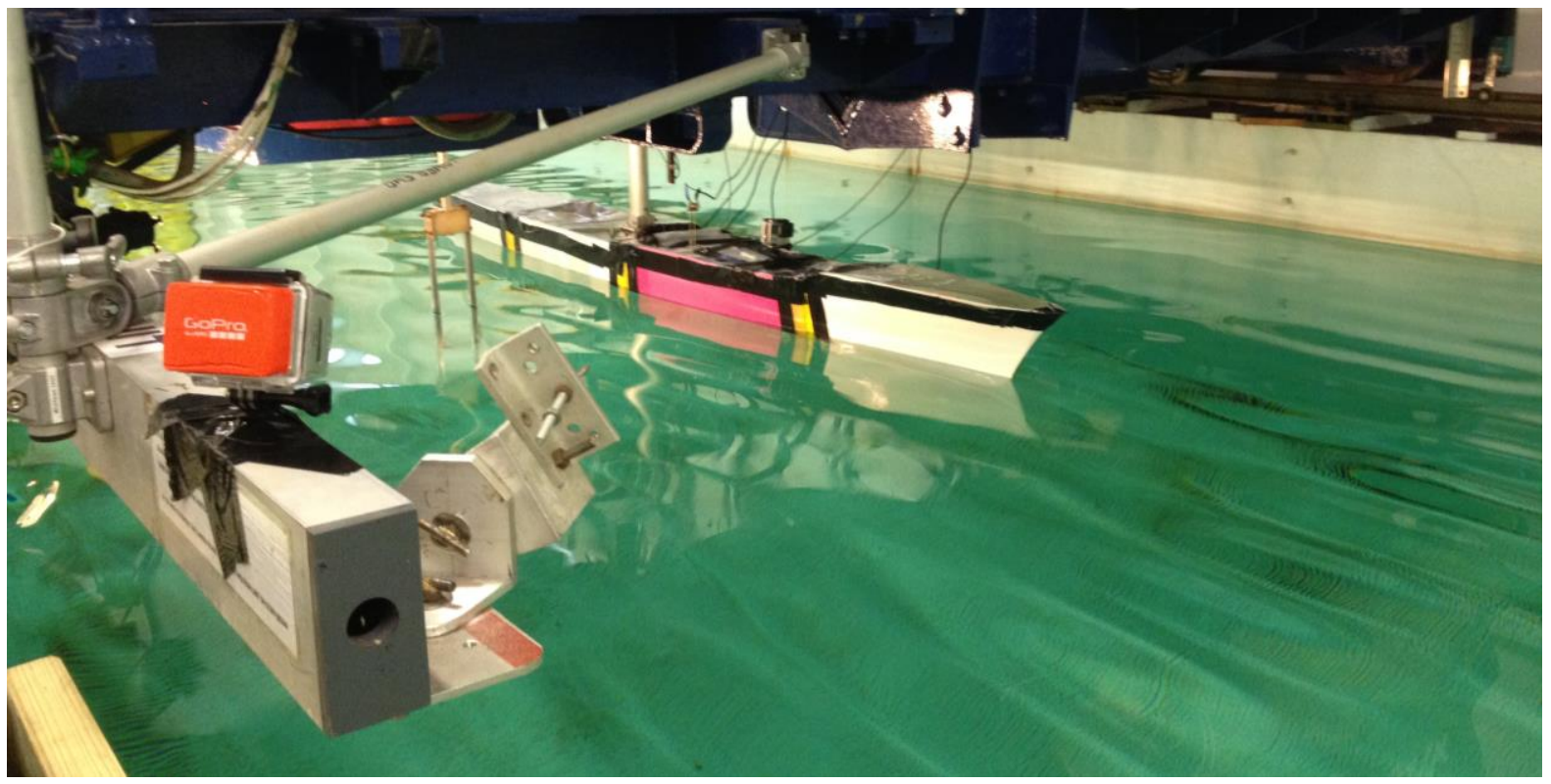

Figure 2: Experimental set-up of the frigate hull. The intact compartments are painted white and the damaged compartment in pink 

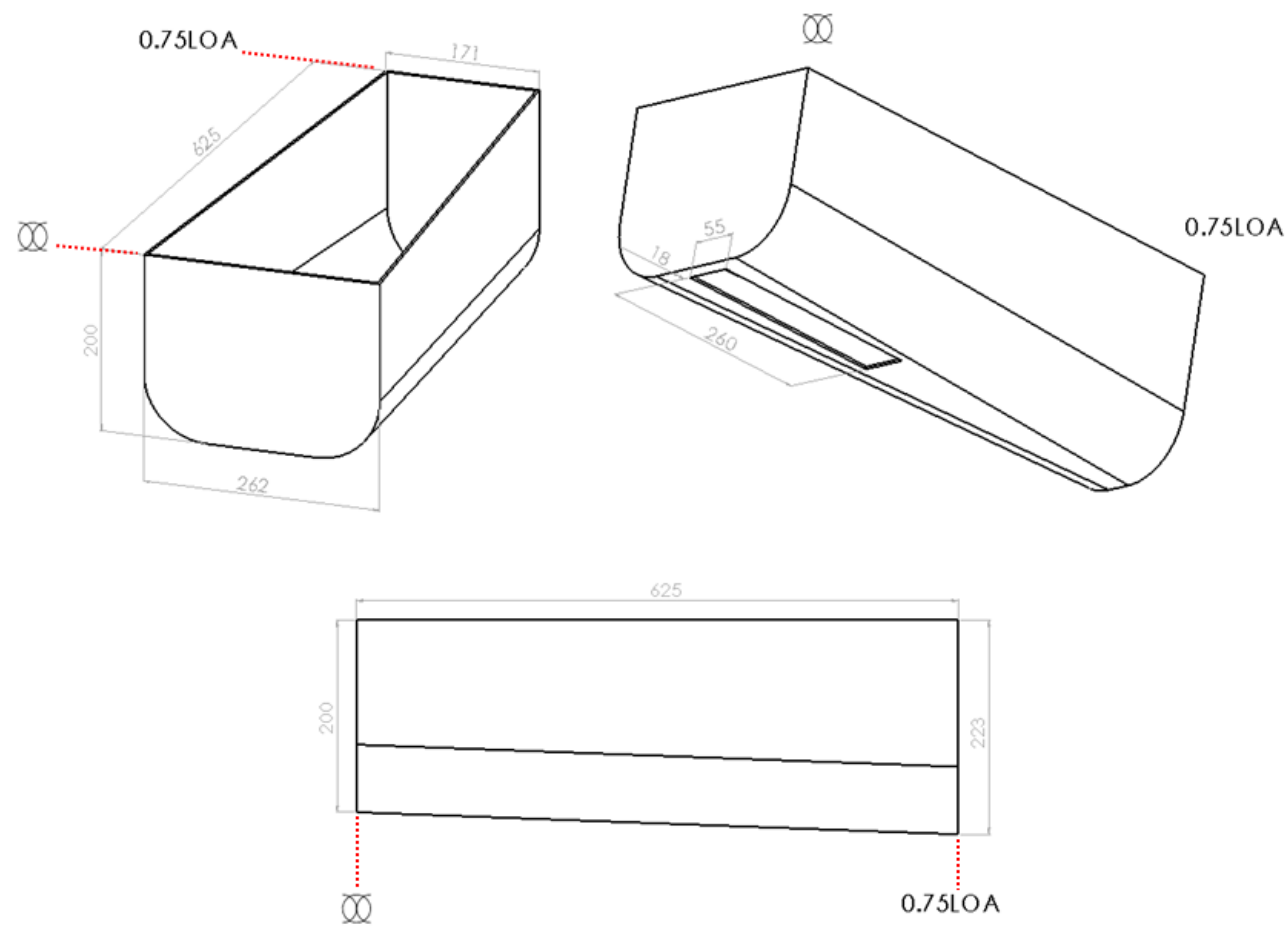

Figure 3: Schematic of damaged compartment

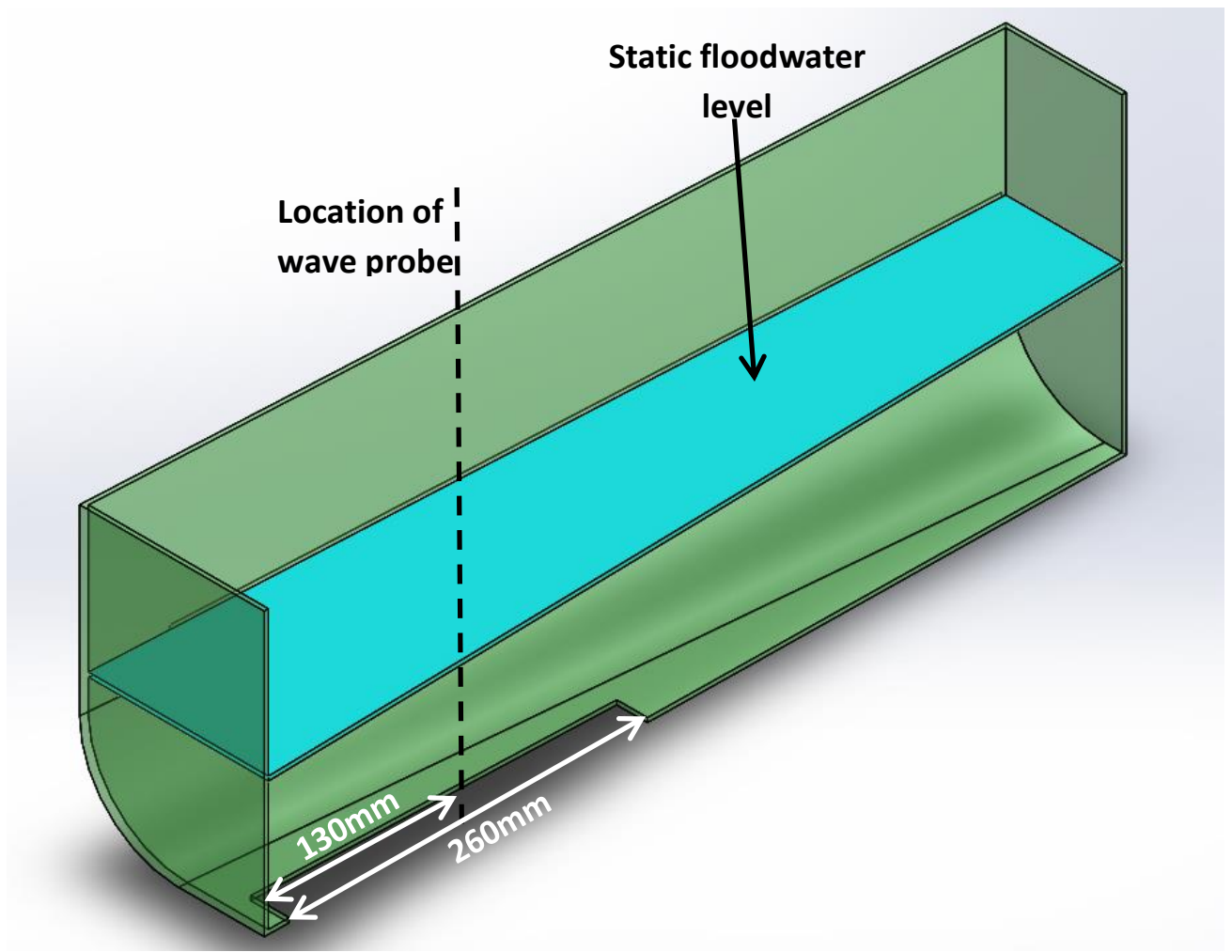

Figure 4: Cross-section through the damaged compartment showing the static floodwater level and the location of the wave probe halfway along the damage opening 

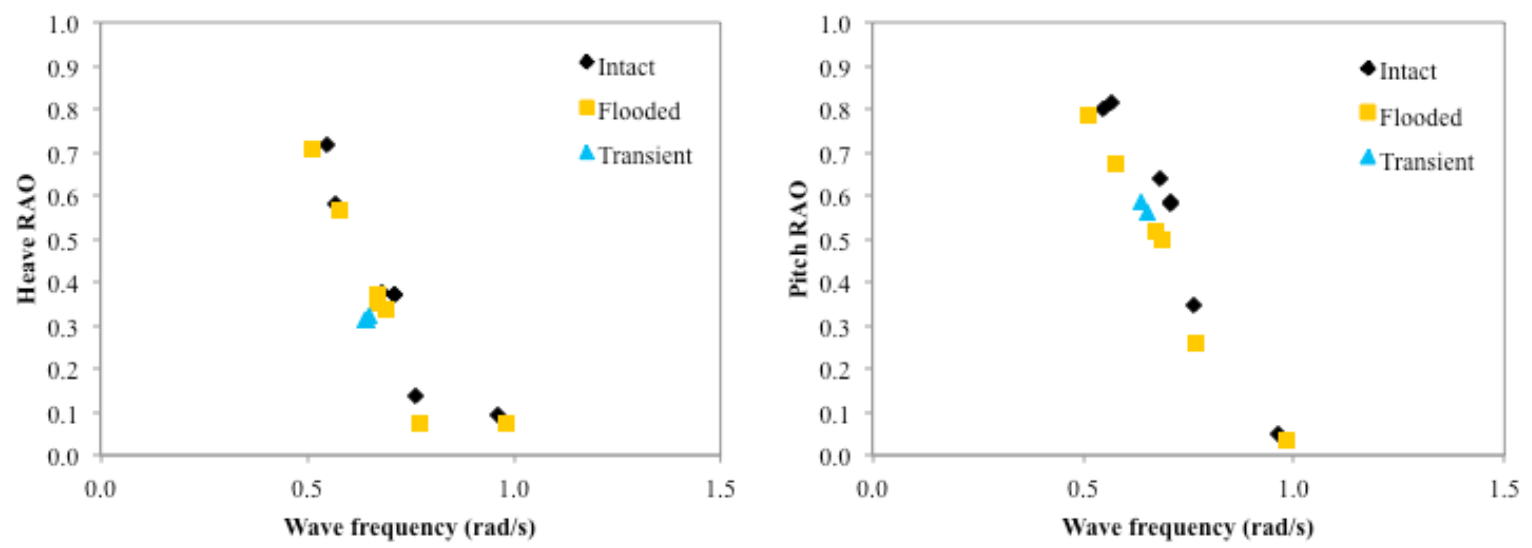

Figure 5: Heave and pitch RAOs measured in the intact, flooded and transient conditions at $F n=0$ (presented full scale)
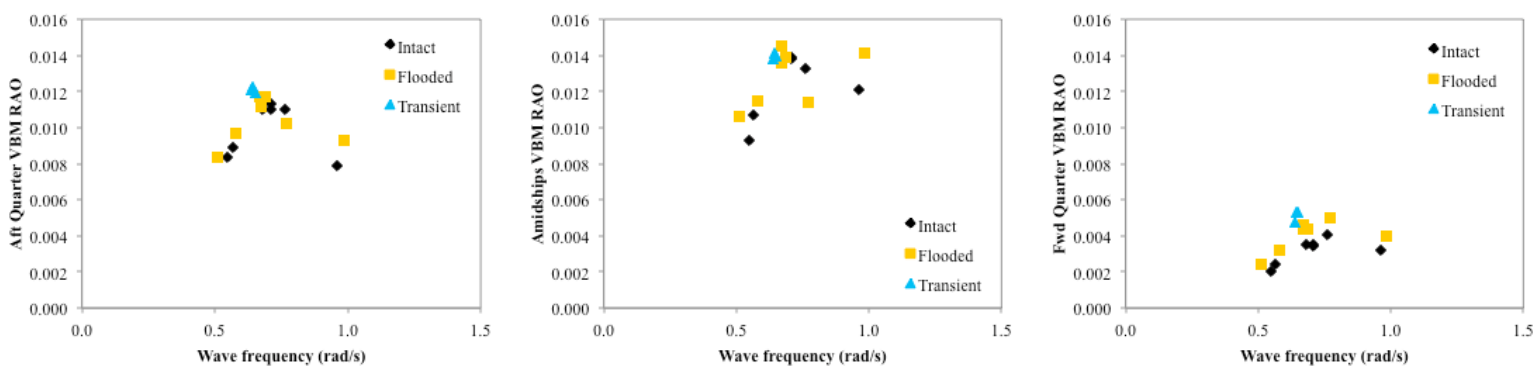

Figure 6: Vertical bending moment RAOs at the forward and aft quarters and amidships for the intact, flooded and transient conditions, at $\mathrm{Fn}=0$ (presented full scale)
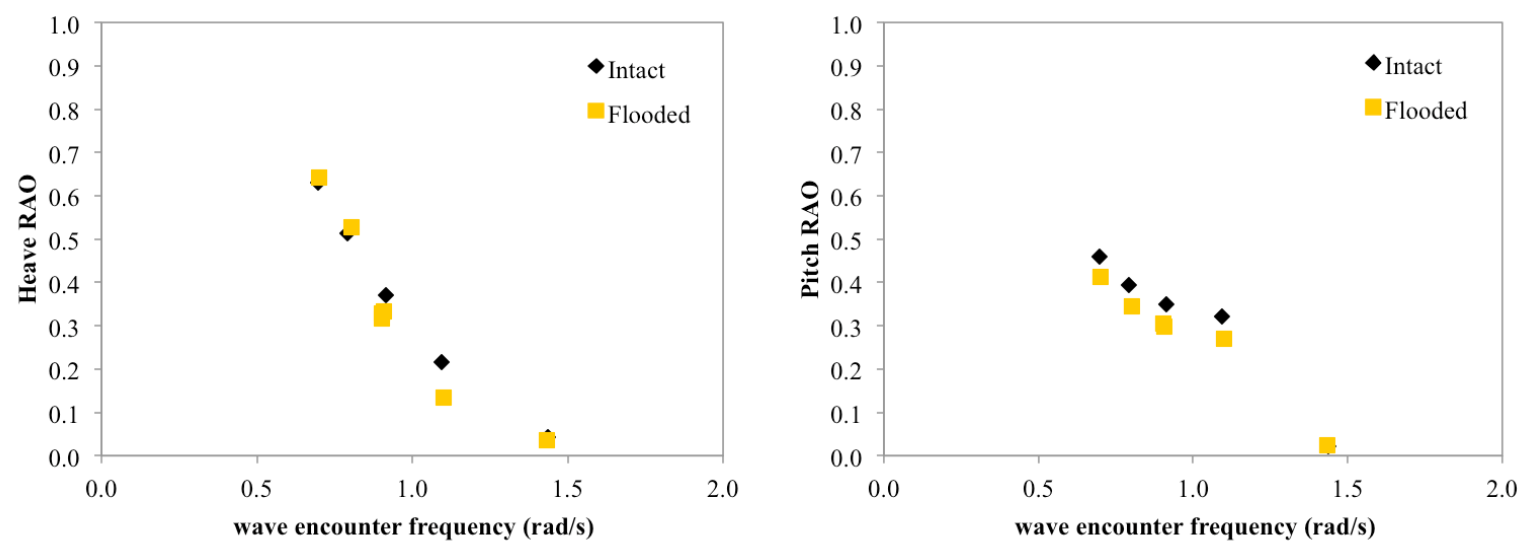

Figure 7: Heave and pitch RAOs measured in the intact and flooded conditions at Fn $=0.157$ (presented full scale) 

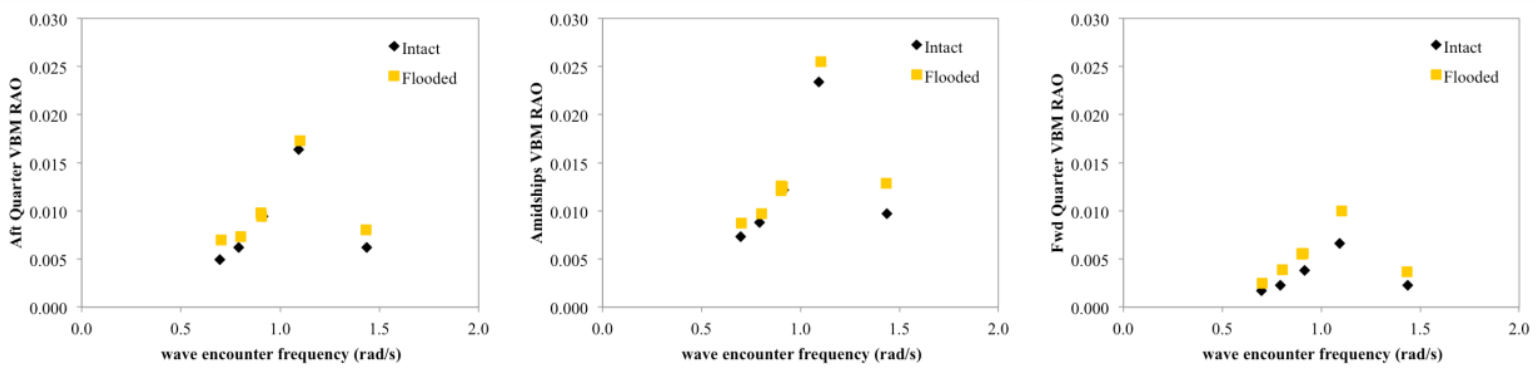

Figure 8: Vertical bending moment RAOs at the forward and aft quarters and amidships for the intact and flooded conditions, at $\mathrm{Fn}=0.157$ (presented full scale)
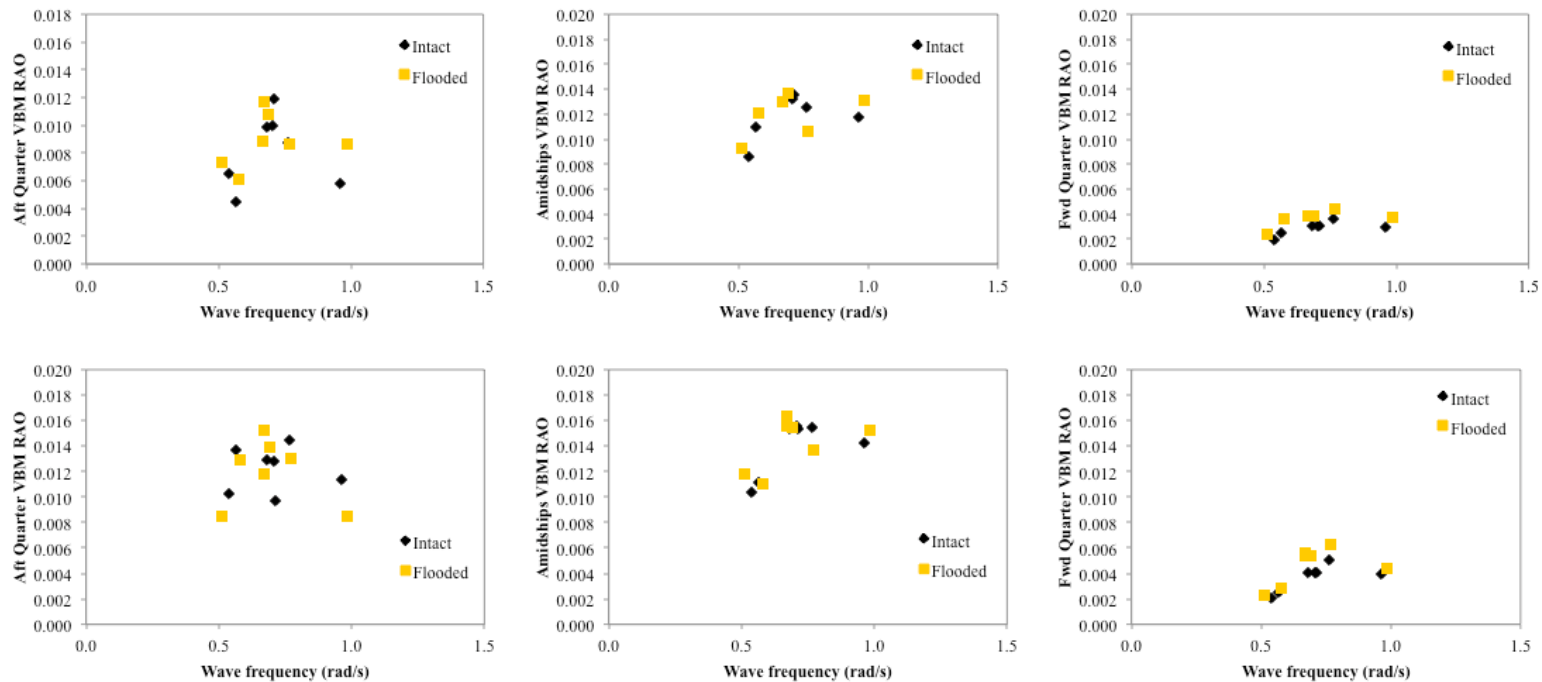

Figure 9: Vertical bending moment RAOs calculated using the double positive amplitude (upper row) and the double negative amplitude (lower row), for $\mathrm{Fn}=0$. Results presented at full scale. 

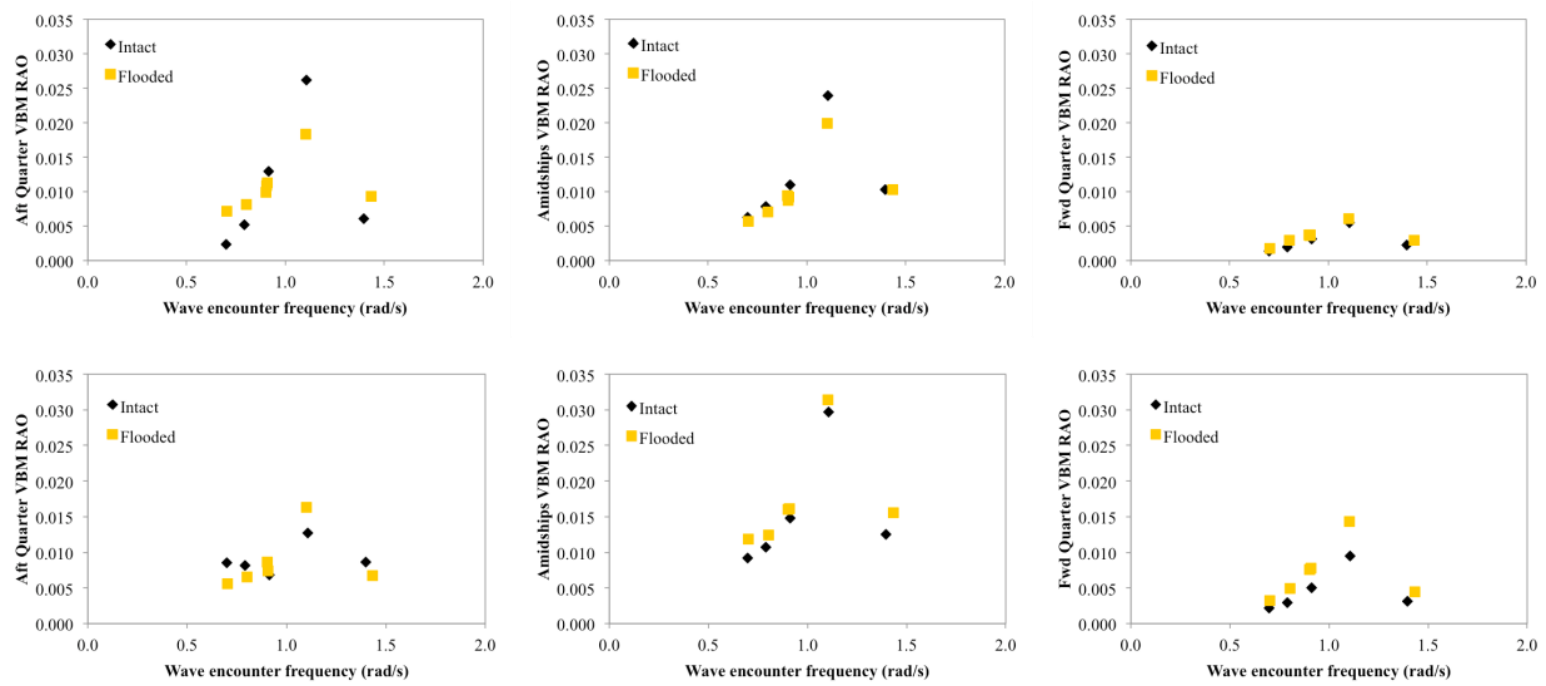

Figure 10: Vertical bending moment RAOs calculated using the double positive amplitude (upper row) and the double negative amplitude (lower row), for $\mathrm{Fn}=0.157$. Results presented at full scale. 

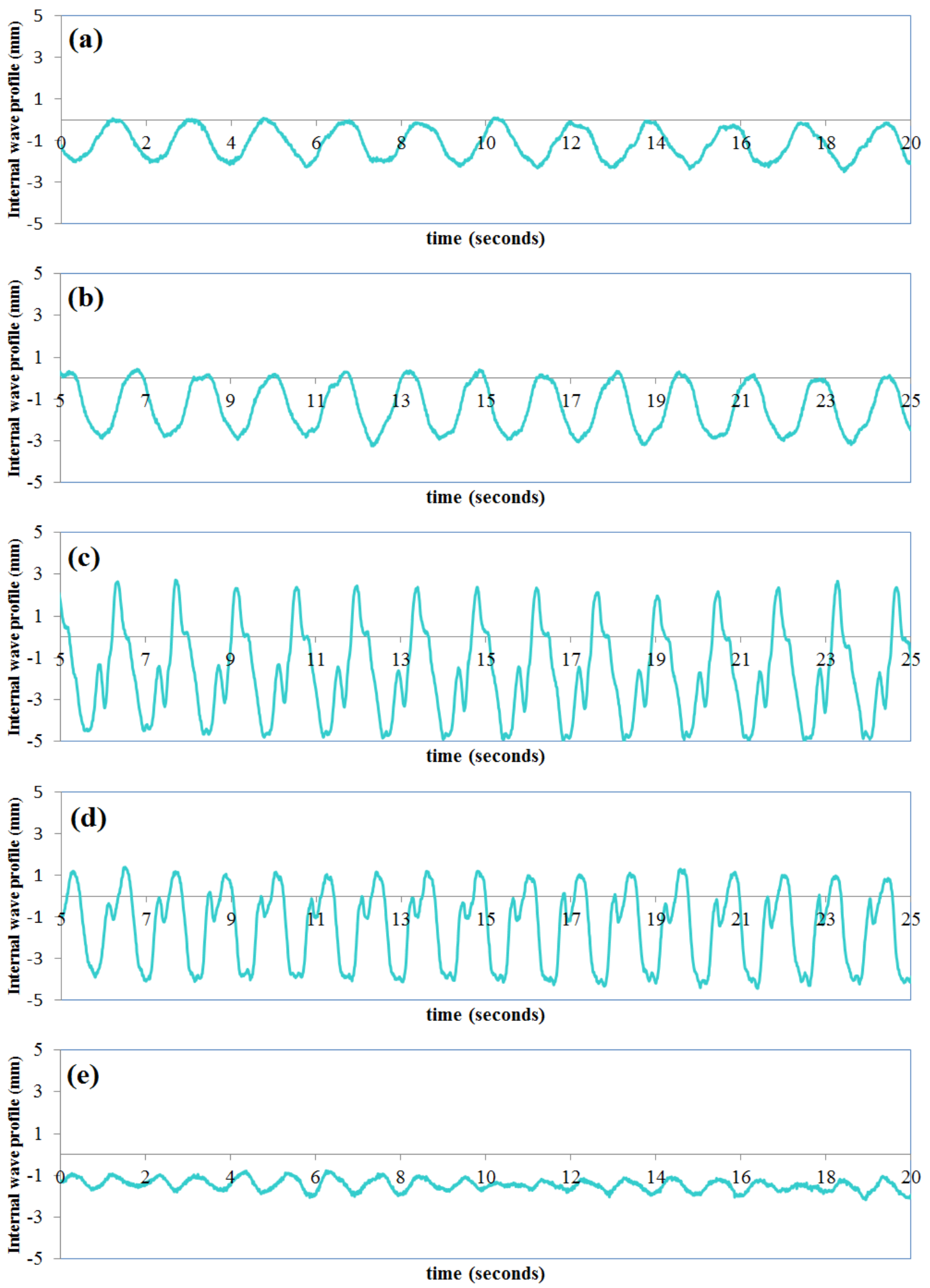

Figure 11: Internal wave profiles at each wave frequency in the flooded condition $(\mathrm{Fn}=0)$. Wave frequencies are (a) $3.49 \mathrm{rad} / \mathrm{s}$, (b) $3.93 \mathrm{rad} / \mathrm{s}$, (c) $4.49 \mathrm{rad} / \mathrm{s}$, (d) $5.23 \mathrm{rad} / \mathrm{s}$, (e) $6.28 \mathrm{rad} / \mathrm{s}$. 

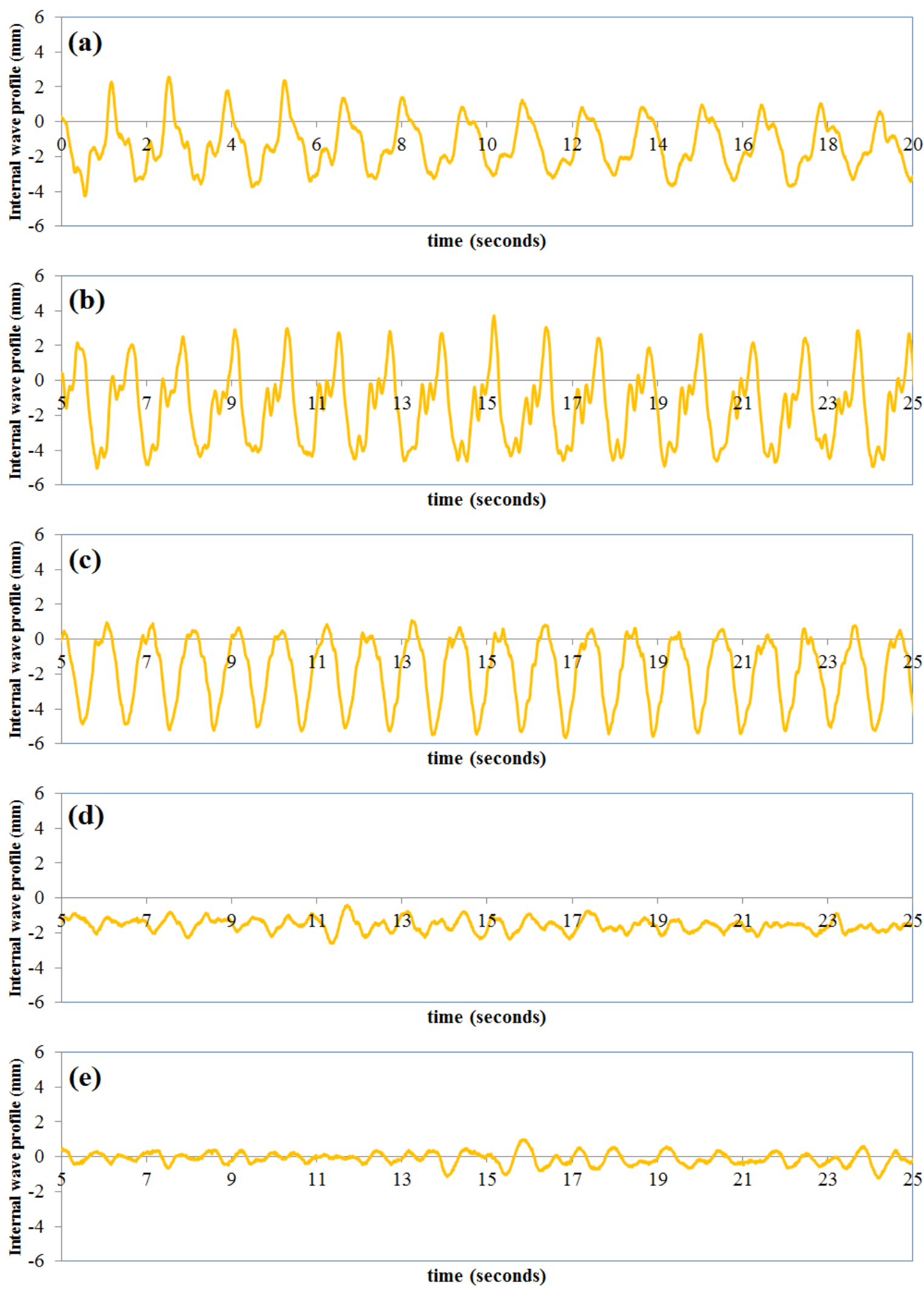

Figure 12: Internal wave profiles at each wave frequency in the flooded condition $(\mathrm{Fn}=0.157)$. Wave frequencies are (a) $3.49 \mathrm{rad} / \mathrm{s}$, (b) $3.93 \mathrm{rad} / \mathrm{s}$, (c) $4.49 \mathrm{rad} / \mathrm{s}$, (d) $5.23 \mathrm{rad} / \mathrm{s}$, (e) $6.28 \mathrm{rad} / \mathrm{s}$. 

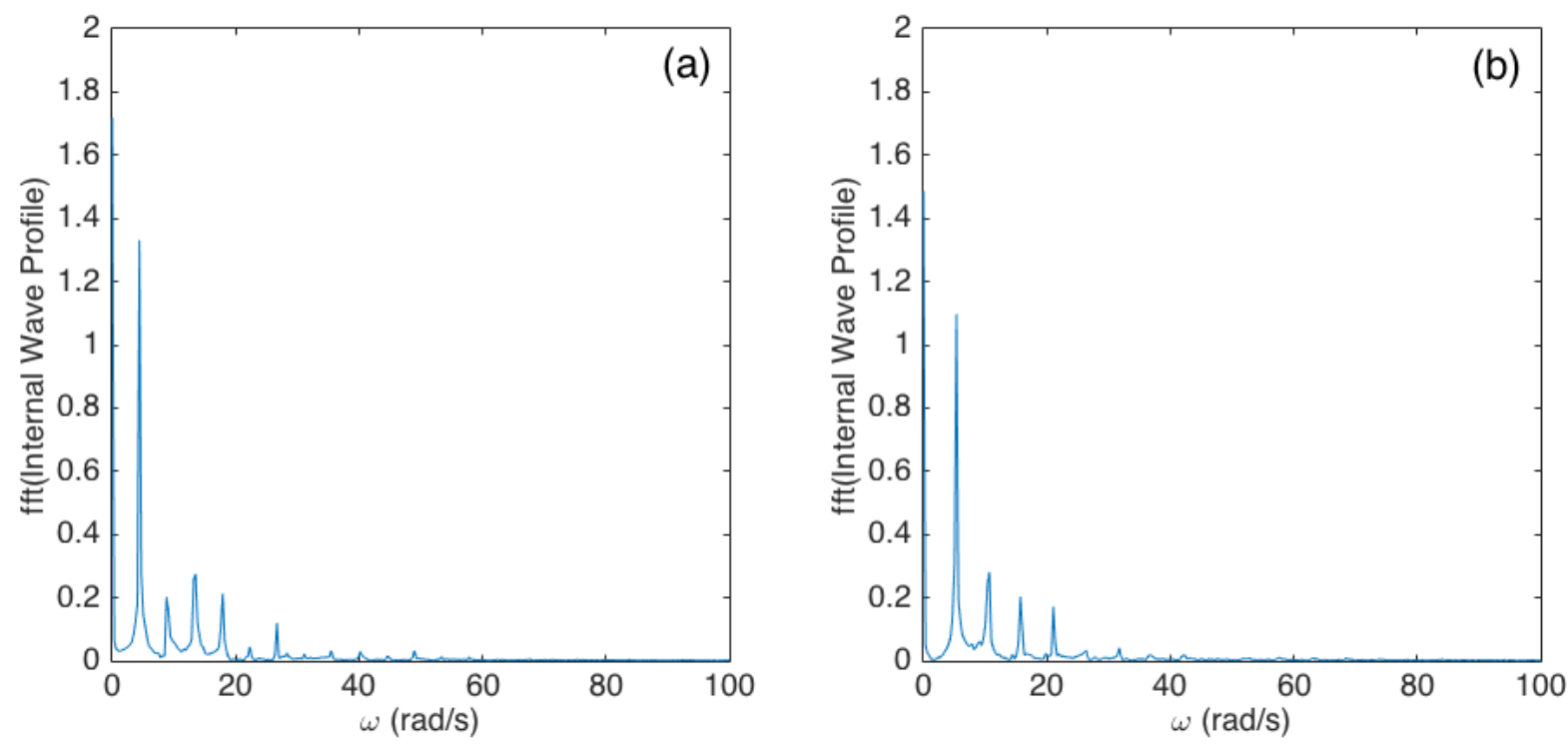

Figure 13: FFT of internal wave profiles for tests in wave frequencies of (a) $4.49 \mathrm{rad} / \mathrm{s}$ (corresponding to Figure 11 (c)) and (b) $5.23 \mathrm{rad} / \mathrm{s}$ (corresponding to Figure 11 (d).
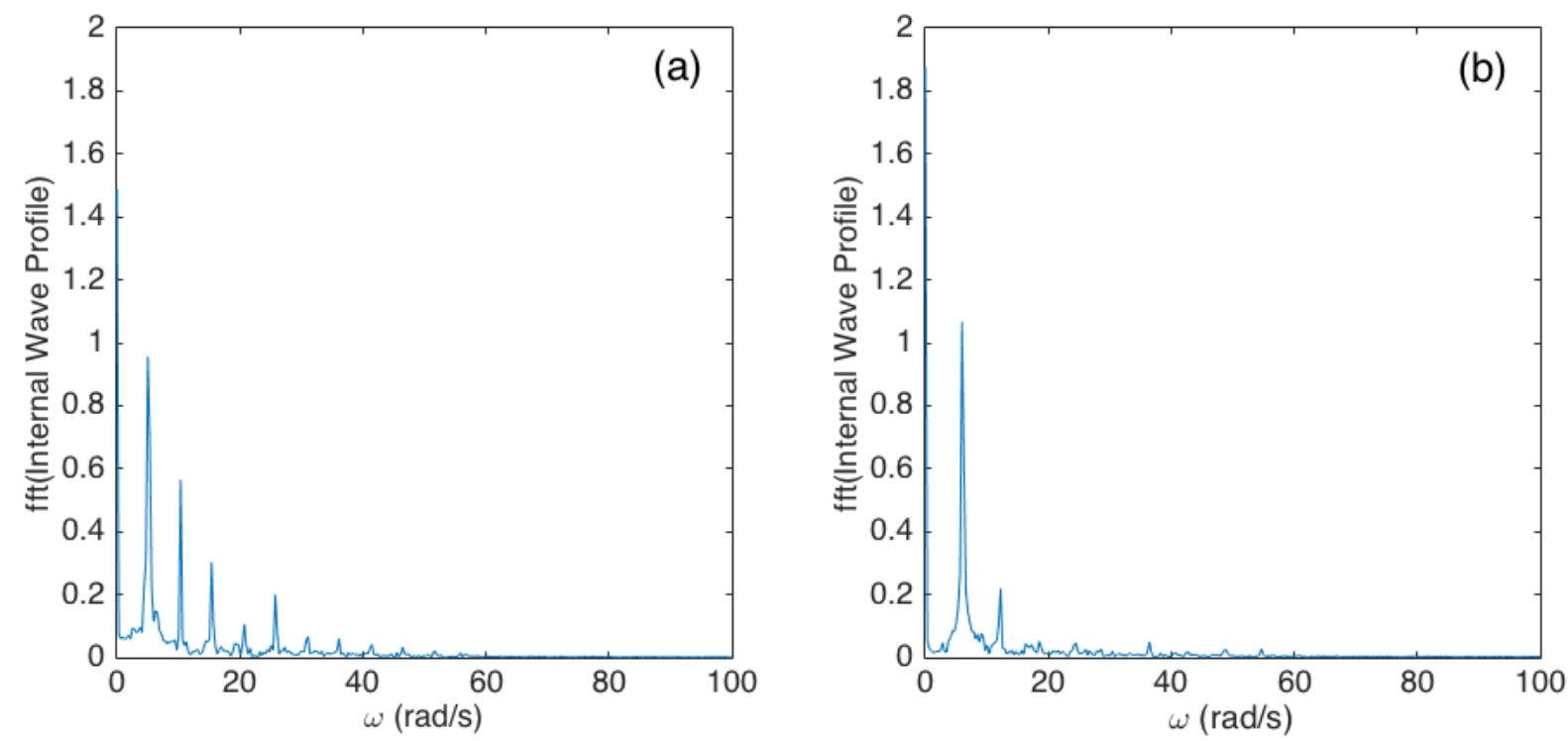

Figure 14: FFT of internal wave profiles for tests in wave frequencies of (a) $3.93 \mathrm{rad} / \mathrm{s}$ (corresponding to Figure 12 (b)) and (b) $4.49 \mathrm{rad} / \mathrm{s}$ (corresponding to Figure 12 (c). 


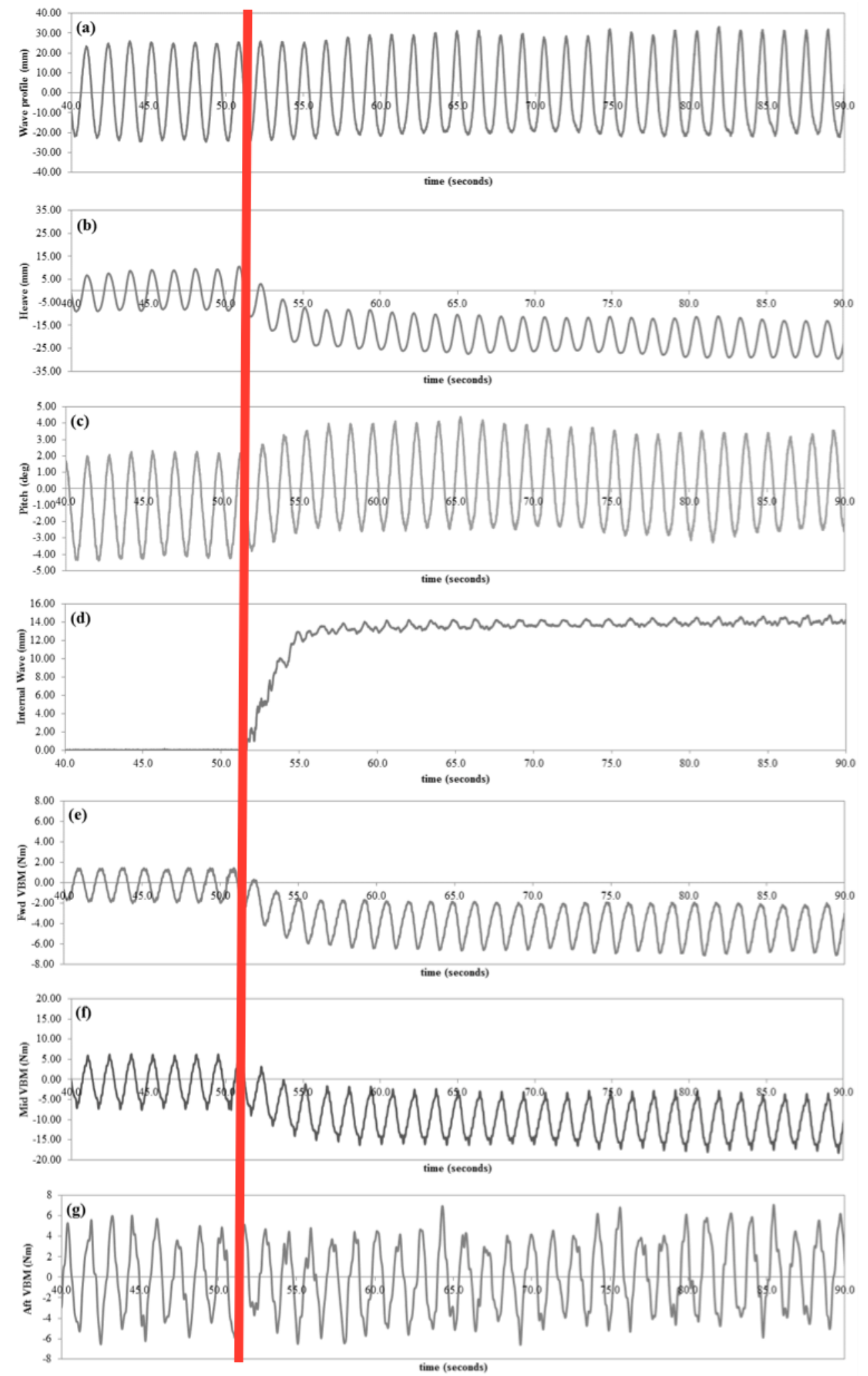

Figure 15: Wave profile and responses recorded during a transient test (presented model scale). The red line indicates the time of the damage occurring. 

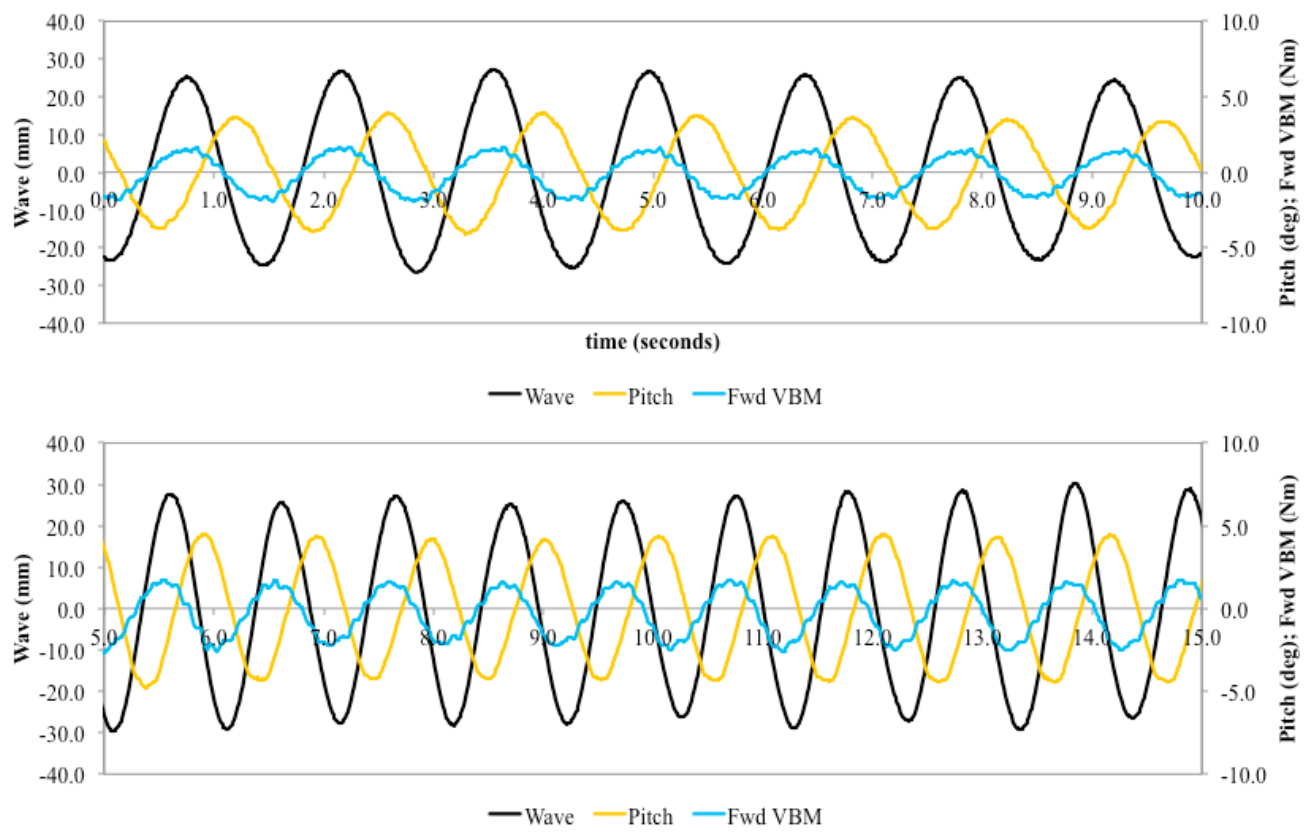

Figure 16: Phasing between wave profiles, pitch response and forward vertical bending moment at Fn $=0$ (upper) and $\mathrm{Fn}=0.157$ (lower) for the intact vessel $\left(\lambda / \mathrm{L}_{\mathrm{OA}}=1.18\right)$
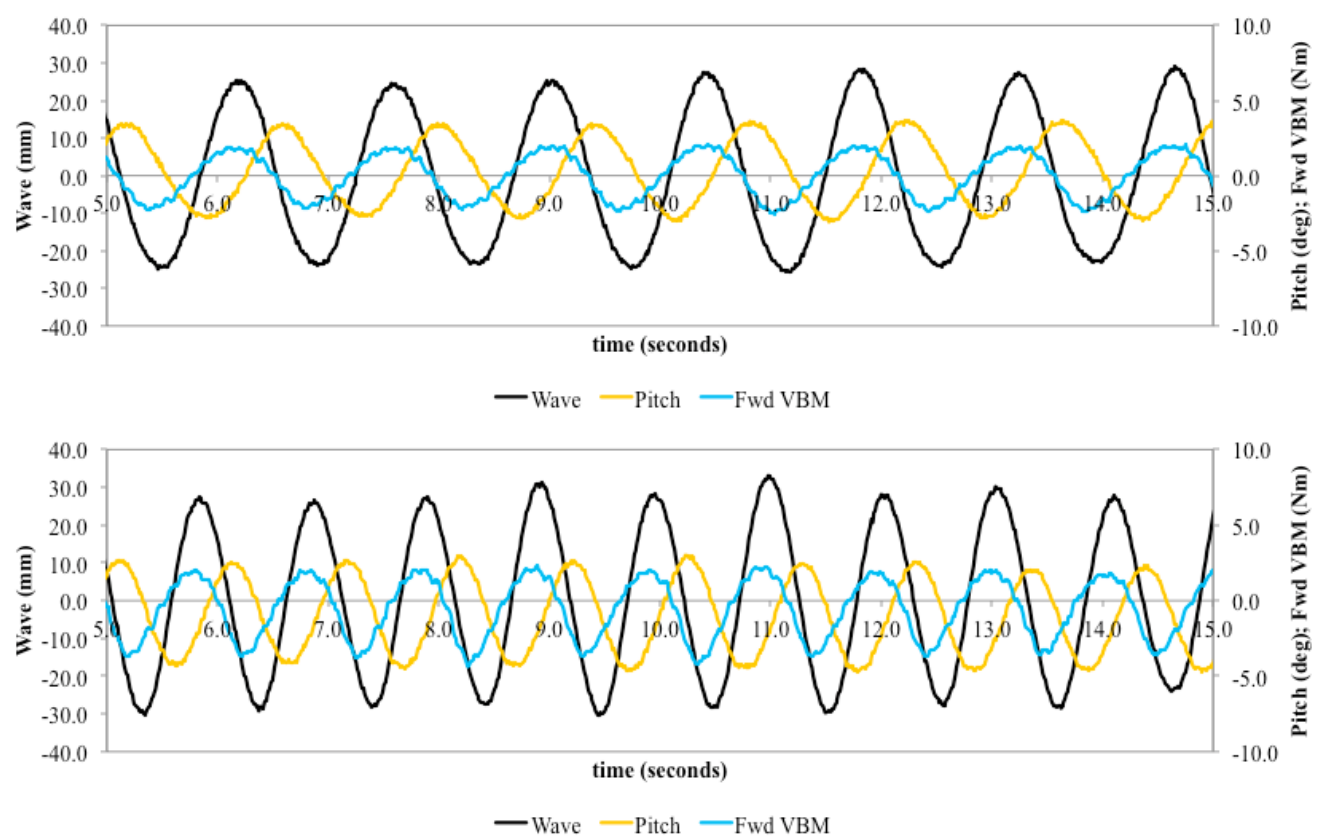

Figure 17: Phasing between wave profiles, pitch response and forward vertical bending moment at Fn $=0$ (upper) and $\mathrm{Fn}=0.157$ (lower) for the flooded vessel $\left(\lambda / \mathrm{L}_{\mathrm{OA}}=1.18\right)$ 

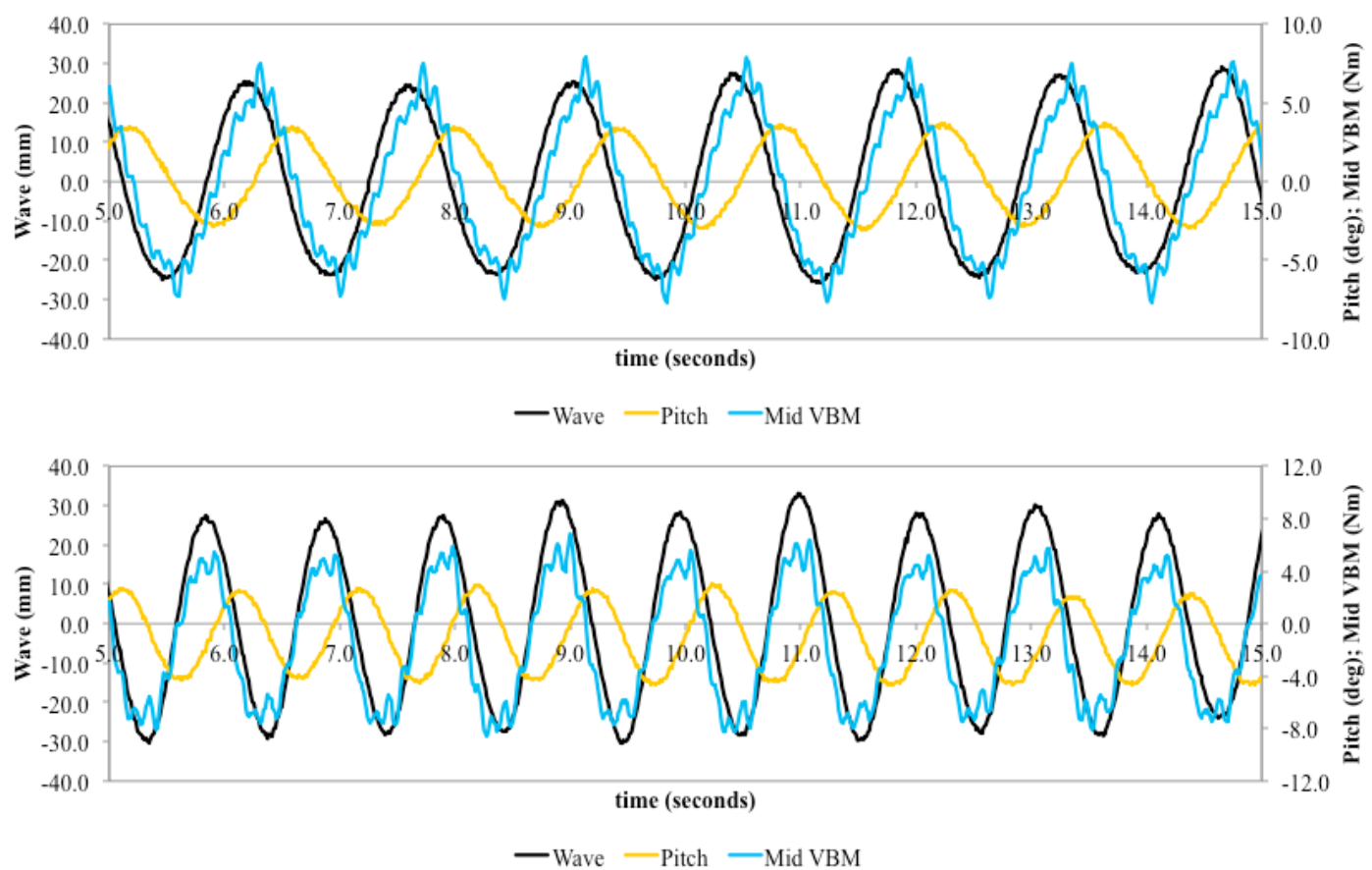

Figure 18: Phasing between wave profiles, pitch response and amidships vertical bending moment at $\mathrm{Fn}=0$ (upper) and $\mathrm{Fn}=0.157$ (lower) for the flooded vessel $\left(\lambda / \mathrm{LOA}_{\mathrm{OA}}=1.18\right)$
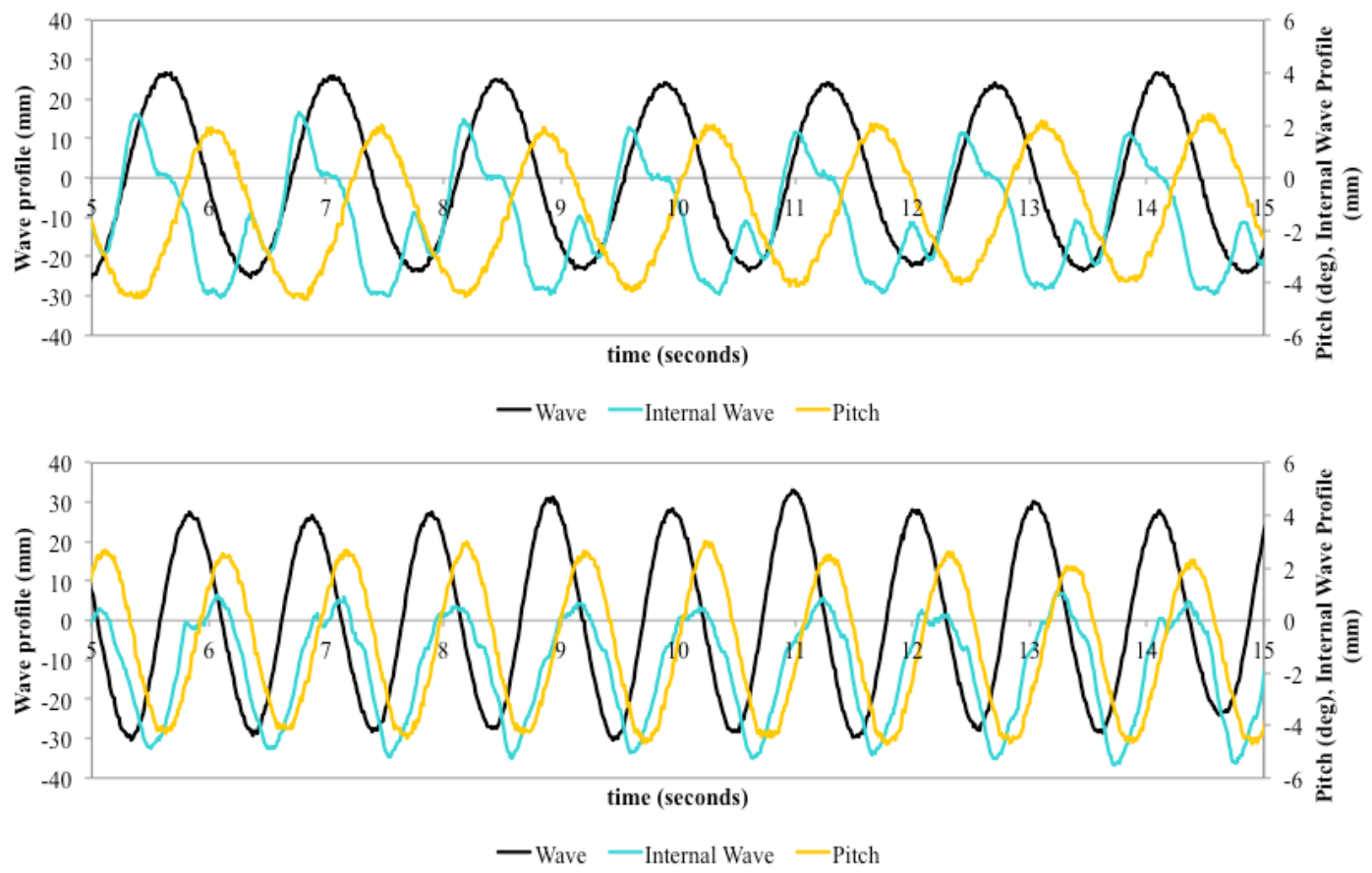

Figure 19: Phasing between wave profiles, pitch response and internal wave profile at $\mathrm{Fn}=0$ (upper) and $\mathrm{Fn}=0.157$ (lower) for the flooded vessel $\left(\lambda / \mathrm{L}_{\mathrm{OA}}=1.18\right)$ 


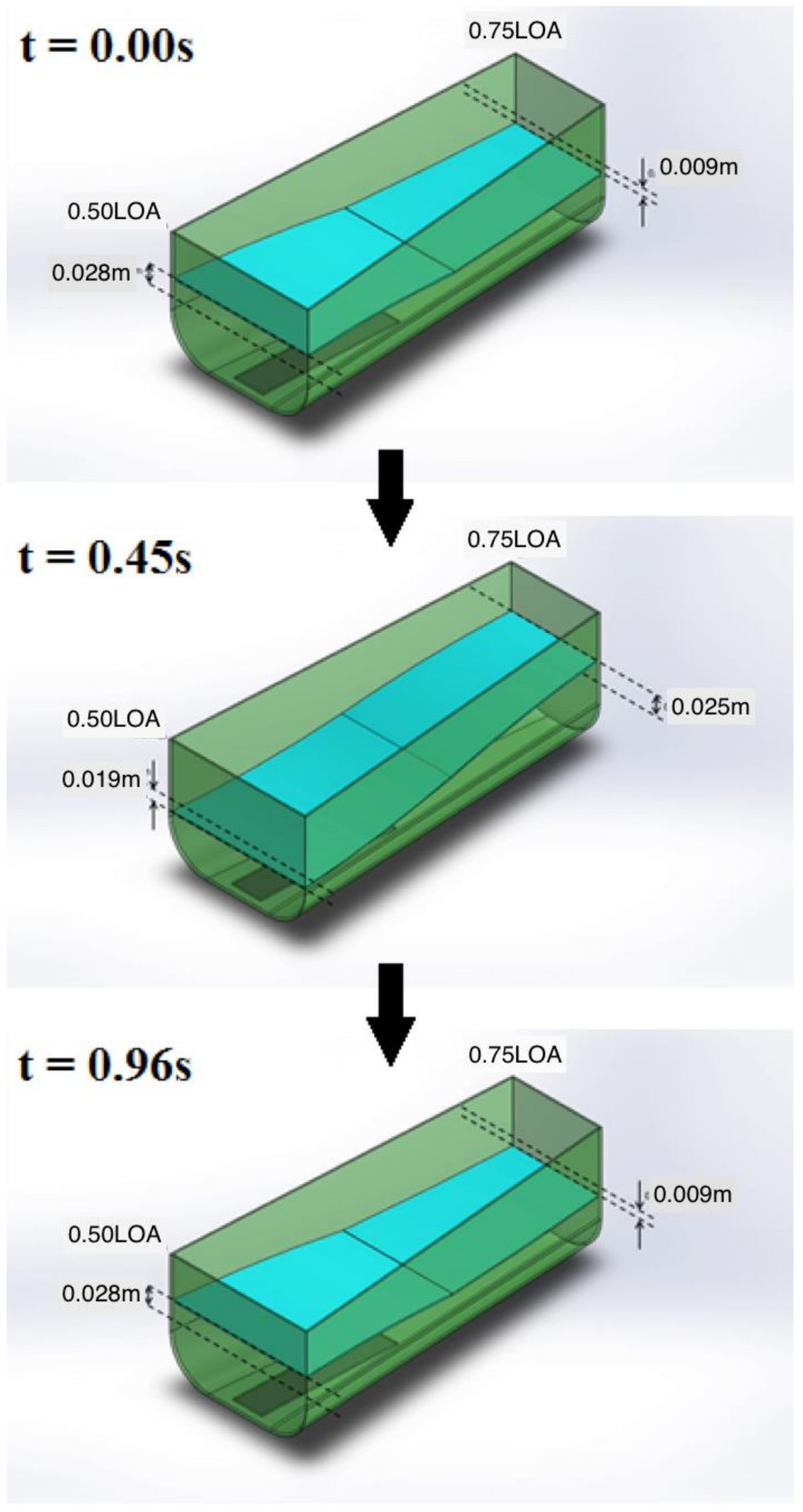

Figure 20: Schematic of floodwater sloshing during transient flooding tests 

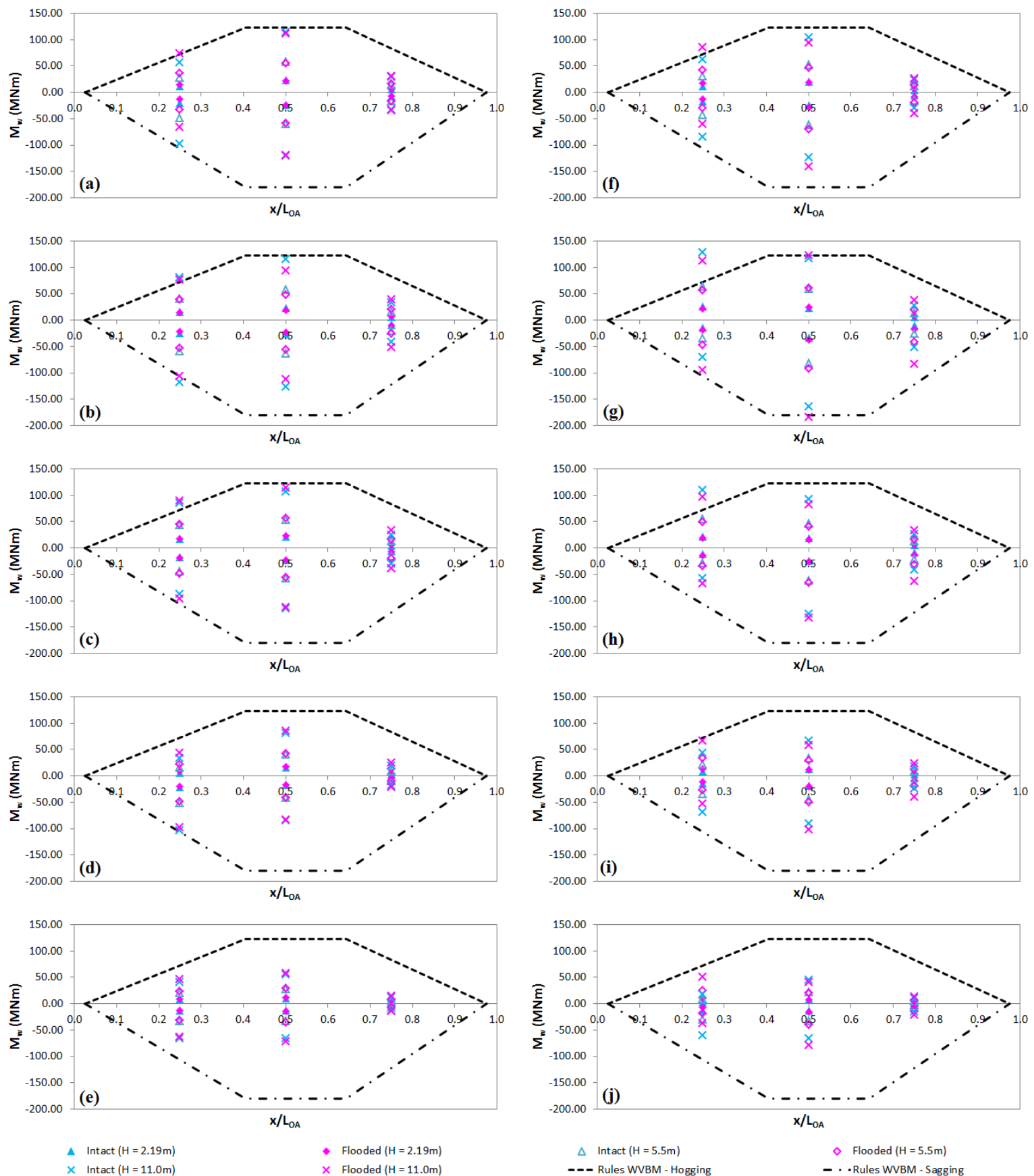

$$
\begin{array}{cc}
\Delta \text { Intact }(H=5.5 \mathrm{~m}) & \diamond \text { Flooded }(H=5.5 \mathrm{~m}) \\
--- \text { Rules WVBM - Hogging } & -\cdots \text { Rules WVBM - Sagging }
\end{array}
$$

Figure 21: Comparison of hogging and sagging experimental vertical bending moment distributions along the ship to classification rules values at wave frequencies of $(\mathrm{a}, \mathrm{f}) 0.95 \mathrm{rad} / \mathrm{s},(\mathrm{b}, \mathrm{g}) 0.79 \mathrm{rad} / \mathrm{s})$, (c,h) $0.68 \mathrm{rad} / \mathrm{s}$, (d,i) $0.59 \mathrm{rad} / \mathrm{s}$ and (e,j) $0.53 \mathrm{rad} / \mathrm{s}$. Results are presented for (a-e) Fn $=0$ and (f-j) Fn $=0.157$. All results are presented full scale. 
TABLES

Table 1: Collision and damage incidents in the last 5 years

\begin{tabular}{|c|c|c|c|c|}
\hline Year & Ship & Incident & Result & Casualties \\
\hline 2015 & $\begin{array}{l}\text { Thorco Cloud cargo ship/Stolt } \\
\text { Commitment }\end{array}$ & Collision & Afloat/sank & $\begin{array}{l}6 \text { out of } 12 \text { crew } \\
\text { missing from } \\
\text { Thorco Cloud }\end{array}$ \\
\hline 2015 & Norwegian Dawn cruise ship & Grounding & Refloated & None \\
\hline 2015 & Hoegh Osaka & Grounding & $\begin{array}{l}\text { Refloated and } \\
\text { repaired }\end{array}$ & 1 injured \\
\hline 2014 & Vectis Eagle general cargo ship & Grounding & $\begin{array}{l}\text { Refloated and } \\
\text { repaired }\end{array}$ & None \\
\hline 2014 & $\begin{array}{l}\text { MV Colombo Express/MV Maersk } \\
\text { Tanjong }\end{array}$ & Collision & Afloat & None \\
\hline 2013 & Maria security vessel/Texal 68 trawler & Collision & Sunk/afloat & 3 missing \\
\hline 2013 & Sima Sapphire/Fishing vessel & Collision & Afloat/sunk & 8 missing \\
\hline 2013 & Eifuku Maru No. 18/Jia Hui & Collision & Capsize/afloat & 6 missing \\
\hline 2013 & MV Smart coal cargo ship & Grounding & $\begin{array}{l}\text { Structure } \\
\text { compromised }\end{array}$ & None \\
\hline 2013 & MV Danio cargo vessel & Grounding & $\begin{array}{l}\text { Refloated and } \\
\text { repaired }\end{array}$ & None \\
\hline 2012 & Costa Concordia cruise ship & Grounding & Sunk & $\begin{array}{l}2 \text { missing } \\
32 \text { deaths }\end{array}$ \\
\hline
\end{tabular}


Table 2: Principal particulars of representative frigate hull

\begin{tabular}{|l|c|c|}
\hline Parameter & Model & Ship \\
\hline Length overall, $\mathrm{L}_{\mathrm{OA}}(\mathrm{m})$ & 2.60 & 113.40 \\
\hline Length between perpendiculars, LBP $(\mathrm{m})$ & 2.52 & 109.72 \\
\hline Breadth, B (m) & 0.29 & 12.36 \\
\hline Draught, T (m) & 0.096 & 4.19 \\
\hline Displacement, $\Delta(\mathrm{kg}$, tonnes) & 29.40 & 2921 \\
\hline Block coefficient, $\mathrm{C}_{\mathrm{B}}$ & 0.406 & 0.485 \\
\hline LCG aft amidships (m) & 0.091 & 3.96 \\
\hline VCG above keel (m) & 0.098 & 4.28 \\
\hline Pitch gyradius (\%LOA) & 24.88 & 25.26 \\
\hline 2-node natural frequency (rad/s) & 94.30 & 14.28 \\
\hline
\end{tabular}

Table 3: Variation in ship parameters with damage condition

\begin{tabular}{|l|c|c|}
\hline Parameter & Intact & Damaged \\
\hline Displacement (tonnes) & 2921.00 & 3883.62 \\
\hline Draught (m) & 4.19 & 5.23 \\
\hline Freeboard (m) & 7.61 & 6.57 \\
\hline LCG aft amidships (m) & 3.96 & -0.52 \\
\hline VCG above keel (m) & 4.28 & 4.77 \\
\hline GMT (m) & 2.11 & 1.56 \\
\hline GML (m) & 207.88 & 150.09 \\
\hline Trim (deg) & 0.259 & 3.06 \\
\hline
\end{tabular}


Table 4: Regular wave parameters at model and full scale

\begin{tabular}{|c|c|c|c|c|c|c|}
\hline \multirow{2}{*}{$\lambda / \mathbf{L O A}$} & \multicolumn{3}{|c|}{ Model scale } & \multicolumn{3}{c|}{ Full scale } \\
\cline { 2 - 7 } & $\lambda(\mathbf{m})$ & $\omega(\mathbf{r a d} / \mathbf{s})$ & $\mathbf{T}(\mathbf{s})$ & $\lambda(\mathbf{m})$ & $\omega(\mathbf{r a d} / \mathbf{s})$ & $\mathbf{T}(\mathbf{s})$ \\
\hline 0.60 & 1.56 & 6.28 & 1.00 & 68.05 & 0.95 & 6.60 \\
\hline 0.87 & 2.25 & 5.23 & 1.20 & 98.15 & 0.79 & 7.93 \\
\hline 1.18 & 3.06 & 4.49 & 1.30 & 133.48 & 0.68 & 9.25 \\
\hline 1.54 & 4.00 & 3.93 & 1.60 & 174.48 & 0.59 & 10.57 \\
\hline 1.95 & 5.06 & 3.49 & 1.80 & 220.72 & 0.53 & 11.89 \\
\hline
\end{tabular}

Table 5: Increase in response from intact to damaged condition as a percentage of the intact response during transient flooding

Average Increase in Response Flooded/Intact (\% of intact response)

\begin{tabular}{|c|c|c|c|c|c|}
\hline Wave & Heave & Pitch & Fwd VBM & Mid VBM & Aft VBM \\
\hline-2.25 & -16.23 & -8.27 & 24.01 & -13.80 & 2.19 \\
\hline
\end{tabular}

Table 6: Movement of zero level of response from intact to damaged condition (full scale)

\begin{tabular}{|c|c|c|c|c|c|}
\hline \multicolumn{7}{|c|}{ Movement of zero level from intact to flooded condition } \\
\hline Wave (m) & Heave (m) & Pitch (rad) & Fwd VBM (MNm) & Mid VBM (MNm) & Aft VBM (MNm) \\
\hline 0.00 & -0.87 & 0.03 & -14.48 & -32.58 & 0.00 \\
\hline
\end{tabular}


Table 7: Location of measured responses on vessel

\begin{tabular}{|l|l|}
\hline Measurement & Distance from amidships measured on vessel (m) \\
\hline Encountered wave profile & 0.0 \\
\hline Pitch & -0.091 \\
\hline Vertical bending moment at forward quarter & +0.625 \\
\hline Internal wave profile & +0.148 \\
\hline
\end{tabular}

Table 8: Uncertainty in experimental measurements at $\mathrm{Fn}=0$

\begin{tabular}{|l|c|c|c|c|c|c|c|c|}
\hline Test & \multicolumn{7}{|c|}{ Uncertainty (\% Average Value over 3 Tests) } \\
\cline { 2 - 9 } Condition & Wave & Wave & Heave & Pitch & VBM & VBM & VBM & Internal \\
& Frequency & Height & & & $(0.75 \mathrm{LOA}$ & $(0.5 \mathrm{LOA})$ & $(0.25 \mathrm{LOA}$ & Wave \\
& & & & & & & & \\
Profile \\
\hline Intact & 5.40 & 1.60 & 3.27 & 2.58 & 3.73 & 3.30 & 3.33 & \\
\hline Flooded & 5.18 & 3.02 & 7.74 & 4.05 & 4.61 & 4.52 & 3.30 & 9.86 \\
\hline Transient & 5.26 & 1.38 & 4.54 & 2.34 & 7.21 & 3.63 & 3.57 & \\
\hline
\end{tabular}

Table 9: Uncertainty in experimental measurements at $\mathrm{Fn}=0.157$

\begin{tabular}{|l|c|c|c|c|c|c|c|c|}
\hline Test & \multicolumn{7}{|c|}{ Uncertainty (\% Average Value over 3 Tests) } \\
\cline { 2 - 9 } Condition & Wave & Wave & Heave & Pitch & VBM & VBM & VBM & Internal \\
& Frequency & Height & & & $(0.75$ LOA & $(0.5$ LOA $)$ & $(0.25$ LOA & Wave \\
& & & & & & & & Profile \\
\hline Flooded & 3.67 & 1.03 & 4.10 & 1.75 & 3.28 & 3.75 & 3.97 & \\
\hline
\end{tabular}

